\title{
La doble imposición en la Directiva 2011/96/UE, del Consejo, de 30 de noviembre de 2011, relativa al régimen fiscal común aplicable a las sociedades matrices y filiales de Estados miembros diferentes
}

Double taxation in Directive 2011/96 / EU, of the Council, of November 30, 2011, on the common tax regime applicable to parent companies and subsidiaries of different Member States

\author{
Francisco MEDINA SUÁREZ \\ info@medinasuarez.es
}

Resumen: El presente estudio aborda la exposición de unas modestas consideraciones sobre los beneficios y aportaciones de la Directiva 2011/96/UE objeto de estudio en la lucha contra la doble imposición internacional en el contexto del mercado interior europeo, así como aquellas cuestiones ciertamente controvertidas que pudiera presentar la norma en su interpretación y aplicación. Todo ello, en aras de intentar arrojar algo de luz que permita superar, en la mayor medida de lo posible, los efectos nocivos de la doble imposición en las operaciones internacionales de financiación de las empresas dentro del marco objetivo de la norma target.

Abstract: The object of this research is the study of a modest considerations over the profits and contributions of Directive 2011/96/UE in the context of the double taxation in the European inside market and these controversial issues for the application and interpretation of this law. It tries to clarify

\footnotetext{
* Este artículo obtuvo, el pasado año académico 2017-2018, el Premio Reina María Cristina, en su sexta edición, en la modalidad de Derecho, patrocinado por el Banco Santander. El jurado calificador estuvo conformado por: D. José Iturmendi Morales (Presidente), Catedrático de Filosofía del Derecho UCM, Decano Emérito de la Facultad de Derecho de la UCM; D. Rafael Navarro-Valls, Catedrático de Derecho Eclesiástico del Estado de la UCM, Vicepresidente de la Real Academia de Jurisprudencia y Legislación; D. José Manuel Armada Vadillo, Asesor Jurídico de la Armada y General Auditor, y D. Francisco José Zamora García (Secretario), Decano de Derecho RCU Escorial-María Cristina.
} 
everything possible the cases provided in this law to avoid the double taxation in the international transaction of business financing within the scope of the target law.

Palabras clave: doble imposición, doble imposición internacional, directiva 2011/96/UE, sociedades matrices y filiales, dividendos, retención en origen, método de exención íntegra, método de imputación, distribución de beneficios, cláusula antiabuso.

Keywords: double taxation, international double taxation, Directive 2011/96/UE, parent companies and subsidiaries, dividends, withholding tax, full exemption method, imputation method, benefit sharing, anti-abuse clause.

\section{Sumario:}

\section{Introducción.}

I. Objetivo y fundamento de la Directiva 2011/96/UE: doble imposición y mercado interior europeo

II. Ámbito objetivo de la Directiva 2011/96/UE y doble imposición.

2.1. El concepto de distribución de beneficios.

2.2. Supuestos de doble imposición.

2.3. Límites al ámbito de aplicación de la Directiva 2011/96/UE. La cláusula antiabuso.

III. Ámbito subjetivo de la Directiva 2011/96/UE y doble imposición.

3.1. Definición de sociedad y presupuestos materiales para evitar la doble Imposición.

3.2. Definición de establecimiento permanente.

IV. Requisitos materiales de aplicación de la Directiva 2011/96/UE y la doble Imposición.

4.1. Porcentaje minimo de titularidad en el capital social.

4.2. Requisitos potestativos de los Estados miembros. 
V. Medidas para evitar la doble imposición sobre la distribución de beneficios en la Directiva 2011/96/UE.

5.1. Medidas para evitar la doble imposición internacional económica.

5.1.1. El método de exención íntegra.

5.1.2. El método de imputación.

5.1.3. Medidas para evitar la doble imposición en el régimen de sociedades transparentes.

5.2. Medidas para evitar la doble imposición internacional jurídica.

VI. Directiva 2011/96/UE vs Modelo de Convenio de la OCDE: avances de la normativa fiscal comunitaria, respecto al Modelo de convenio de la OCDE en los supuestos de doble imposición sobre la distribución de beneficios.

VII. Referencias bibliográficas. 



\section{INTRODUCCIÓN}

El problema de la doble imposición sobre la distribución de beneficios de los grupos societarios internacionales representa uno de los fenómenos más importantes en las operaciones de financiación de las empresas. La tributación de los beneficios distribuidos en la esfera internacional puede erigir discriminaciones y distorsiones que impiden la inversión y el accionariado transfronterizo ${ }^{1}$ e incidir negativamente en las actividades económicas comunitarias ${ }^{2}$ dentro del mercado interior europeo. Estas perturbaciones provienen de la influencia tanto de la doble imposición que soportan esas rentas, como de los distintos métodos previstos para su corrección. Por ello, este artículo aborda un modesto estudio sobre los beneficios y aportaciones de la Directiva 2011/96/UE en la lucha contra el fenómeno de la doble imposición internacional en el contexto del mercado interior europeo, así como algunas cuestiones controvertidas que inciden en la aplicación de la norma comunitaria para, finalmente, compararla con los preceptos del Modelo de Convenio de la OCDE para evitar la doble imposición sobre estas fuentes de renta.

Los antecedentes de la Directiva 2011/96/UE ${ }^{3}$ datan de la década de los años 60 con la Propuesta de Directriz del Consejo concerniente al régimen fiscal común aplicable a las sociedades matrices y filiales de Estados miembros diferentes

\footnotetext{
${ }^{1}$ RUDING, «Informe del Comité Ruding: conclusiones y recomendaciones del Comité de Expertos Independientes sobre la imposición de sociedades», in Office for oficial Publications of the European Communities (Bruselas), (1992) 223-224.

2 Bolkestein, citado en MARÍN BENÍTEZ, G., «Fiscalidad de los dividendos transfronterizos en la Unión Europea: sobre la adecuación de la normativa española al derecho comunitario»«, en Revista de Contabilidad y Tributación (Madrid), 271 (2005) 8. RUBIO GUERRERO, J. J., «Los principios básicos de la fiscalidad internacional y la doble imposición internacional», en Manual de Fiscalidad Internacional, Madrid 2001, pp. 40-69. SOUSA SANTOS AGUIAR, N. T., «La fiscalidad de los beneficios societarios y de los capitales en la Unión europea. Principios fundamentales», en Revista de Contabilidad y Tributación (Madrid), $262(2005) 34$.

${ }^{3}$ Modificada en su artículo 1.2 por la Directiva (UE) 2015/121, del Consejo, de 27 de enero, por la que se modifica la Directiva 2011/96/UE relativa al régimen fiscal común aplicable a las sociedades matrices y filiales de Estados miembros diferentes (DOUE L 21, de 28 de enero de 2015)
} 
presentada por la Comisión al Consejo el 16 enero 19694; la Propuesta de Directriz del Consejo concerniente a la armonización de los sistemas de impuestos sobre las sociedades y de los regímenes de retención en la fuente sobre los dividendos presentada por la Comisión al Consejo, el 1 de agosto de $1975^{5}$ y, fundamentalmente, la Directiva 90/435/CE que erige la antesala de la actual Directiva fiscal europea en vigor en tanto en cuanto esta última comprende una versión consolidada de la primera junto a las modificaciones por vía jurisprudencial ${ }^{6}$ y legislativa $^{7}$.

\section{OBJETIVO Y FUNDAMENTO DE LA DIRECTIVA 2011/96/UE: DOBLE IMPOSICIÓN Y MERCADO INTERIOR EUROPEO}

La Directiva 2011/96/UE señala sus objetivos y fundamentos esenciales en el preámbulo de la misma. Así, la norma apunta como fundamento principal de su adopción la existencia de disparidades entre los diferentes sistemas fiscales de los países miembros que pueden representar un obstáculo en el ejercicio de las libertades fundamentales que erigen la piedra angular del mercado interior impidiendo su buen funcionamiento. Tales disparidades pueden deberse, entre otras razones, a medidas destinadas al proteccionismo económico, medidas incentivadoras, etc., de cada Estado miembro ${ }^{8}$. A tal fin, se considera necesario no dificultar la creación de grupos empresariales multinacionales en el marco comunitario mediante restricciones, desventajas o distorsiones particulares derivadas de las disposiciones fiscales de los diferentes Estados miembros ${ }^{9}$, así como establecer normas fiscales neutras, respecto a la competencia con la finalidad de permitir que las empresas se adapten a las exigencias del mercado interior, aumentar su productividad y reforzar su posición de competitividad en el plano internacional, evitando deslocalizaciones de las entidades filiales por razones de la tributación en la fuente ${ }^{10}$; evitar discriminaciones en las relaciones

\footnotetext{
${ }^{4}$ DOCE $n^{\circ}$ C 39, 22 de marzo de 1969.

${ }^{5}$ DOCE, $\mathrm{n}^{\circ} 253$, de 5 de noviembre de 1975.

${ }^{6}$ Sentencia del Tribunal de Justicia de las Comunidades Europeas, asunto C-133/06, Compagnie de Saint-Gobain \& Zweigniederlassung Deutschland, de fecha 21-9-1999.

${ }^{7}$ Directiva 2003/123/CE del Consejo, DOCE L 7 de 13-1-2004; y Directiva 2006/98/CE del Consejo, DOCE L 363 DE 20-12-2006. Nos referimos a las modificaciones sustantivas de la que ha sido objeto durante su vigencia (el artículo 9 de la Directiva 2011/96/UE derogó la Directiva 90/435/CE) excluyendo las referidas a las Actas de adhesión de 1994 y 2003.

${ }^{8}$ VARIOS, La armonización fiscal en la comunidad económica europea y el sistema tributario español: incidencia y convergencia, Madrid 1990, pp. 16-17.

${ }^{9}$ En el mismo sentido, LETE ACHIRICA, C., «Régimen fiscal de las distribuciones de beneficios entre sociedades filiales y sociedades matrices», en Impuestos (Madrid), 2 (1996) 432. SÁNCHEZ JIMÉNEZ, Ma . A., La doble imposición internacional en la Unión Europa. Especial consideración del Impuesto de Sociedades, Madrid 1995, p. 167.

${ }^{10}$ En un sentido similar, RODRÍGUEZ ONDARZA, J. A., $<<$ Fiscalidad de la inversión societaria: un estudio comparado para la Unión Europea $\gg$, en Hacienda Pública Española
} 
entre sociedades matrices y filiales en el mercado nacional de los diferentes Estados miembros, respecto a aquellas que se desarrollan en el plano económico internacional europeo ${ }^{11}$; y con todo ello, facilitar la creación de grupos de sociedades de Estados miembros diferentes.

El objetivo esencial de la norma es facilitar la cooperación, ampliación e integración de los grupos societarios europeos mediante la eliminación de cualquier penalización como la retención en origen u otras penalizaciones similares o análogas como la doble imposición ${ }^{12}$ sobre las rentas derivadas de dividendos y otros beneficios transfronterizos distribuidos por filiales a sus sociedades matrices o por filiales al establecimiento permanente o alguno de la sociedad matriz ${ }^{13}$. Esto último mediante la exención de dicha rentas en el país de residencia o por la concesión de un crédito fiscal a la sociedad matriz en la cuota líquida del impuesto de sociedades equivalente a la fracción del impuesto que aquélla haya satisfecho favoreciendo la creación y consolidación del mercado interior europeo (párrafos séptimos y octavo del preámbulo).

A nuestro humilde parecer, la claridad y precisión de los fundamentos y objetivos de la Directiva 2011/96/UE representa un instrumento de gran utilidad para garantizar la plena eficiencia y eficacia de la norma evitando no solamente la doble imposición en los términos definidos en la misma sino también la posible aplicación de supuestos de doble imposición encubiertos o sobreimposiciones

(Madrid), 136 (1996) 123. PRÓSPER ALMAGRO, A. B., «El nuevo escenario jurídico de la tributación de los dividendos entre España y los Estados Unidos de América», en Revista de Contabilidad y Tributación (Madrid), 37434 (2014) 25.

11 La Directiva 2011/96/UE expone la diversidad de disposiciones fiscales en los diferentes países comunitarios con anterioridad a la entrada en vigor de la Directiva 90/435/CE que creaban estas discriminaciones, lo cual ponía de manifiesto la conveniencia de establecer un régimen común para facilitar la creación de estos grupos de sociedades en el marco de la Unión Europea. Ello dio lugar a la aprobación de la Directiva 90/435/CE y, finalmente, a la Directiva 2011/96/UE fundamentada en soslayar discriminaciones por razón de la nacionalidad o residencia entre los grupos de sociedades naciones e internacionales. MARÍN BENÍTEZ, G., «Fiscalidad de los dividendos transfronterizos...cit., 8. La autora afirma que las perturbaciones que puede generar en el mercado interior europeo una distinta fiscalidad de los dividendos provienen tanto de la influencia de la doble imposición sobre dichas rentas como los diferentes mecanismos para evitarla que, a la postre, influyen en las decisiones de inversión transfronteriza de los agentes económicos». IZQUIERDO LLANES, G., El futuro de la tributación del capital en Europa, Madrid 1997, p. 111.

${ }^{12}$ Sentencia del Tribunal de Justicia de las Comunidades Europeas, Banque Fédérative du Crédit Mutuel, apartados 24 y 27.

${ }^{13}$ Sentencia del Tribunal de Justicia de las Comunidades Europeas, asunto C-375/98 ${ }^{13}$, Ministerio Público \& Fazenda Pública \& Epson Europe BV. En este caso, la Corte comunitaria señalaba como finalidad de la Directiva: mediante el establecimiento de un régimen tributario común, eliminar toda penalización a la cooperación entre sociedades de un mismo Estado miembro para facilitar la integración de los grupos societarios comunitarios. 
fiscales con fines compensatorios por parte de las autoridades fiscales de los Estados miembros en tanto en cuanto los objetivos de dicha norma en concordancia con los previstos en los tratados originarios constituyen una base de interpretación esencial $^{14}$.

\section{II. ÁMBITO OBJETIVO DE LA DIRECTIVA 2011/96/UE Y DOBLE IMPOSICIÓN}

El ámbito objetivo de esta norma comprende solamente las distribuciones de beneficios intracomunitarios, es decir tanto el origen como el destino de los beneficios distribuidos debe producirse dentro del ámbito del mercado interior europeo.

\subsection{El concepto de distribución de beneficios}

Las fuentes de renta comprendidas en el ámbito objetivo de la norma target comprende cualquier distribución de beneficios descrita en la casuística del artículo 1, salvo las distribuciones realizadas con motivo de la liquidación de la entidad que los distribuye (ex. artículo 4.1). La Directiva 2011/96/UE no define en ningún precepto lo que debe entenderse por distribución de beneficios, aunque los artículos 1, 4.1, 5 y 7 parecen aportar elementos para determinar la fuente de renta objetiva. La ausencia de una definición de "distribución de beneficios" y la abstracción del término en consonancia con los fundamentos

${ }^{14}$ En la Sentencia del Tribunal de Justicia de las Comunidades Europeas (actualmente, la denominación oficial de la Corte de Luxemburgo es el Tribunal de Justicia de la Unión Europea), asunto Humblet, de fecha 16 de diciembre de 1960, mostró la prevalencia del método sistemático "contexto general" (así como en las Sentencias del Tribunal de Justicia de las Comunidades Europeas, asunto C-59/75 Manghéra, de 3-2-1976; asunto C-75/63 Unger, de 19-3-1964; asunto C-2-3/62, Com. \& c/Luxemburgo y Bélgica, de 14-12-1962; asunto C26/62, Van Gend y Loos, de 5-2-1963; asunto C-33/70, SACE de Bérgamo, de 17-12-1970; asunto C-4/69, Lütticke, de 28-4-1971); del método teleológico, es decir "el objeto y el fin" cabría señalar las Sentencias del Tribunal de Justicia de las Comunidades Europeas, asunto Humblet, de fecha 13 de marzo de 1973, asunto C-61/72, Mij PPV; y asunto C-6/74, Moulijn, de 21-11-1974); de la interpretación, conforme a sus objetivos, las Sentencias del Tribunal de Justicia de las Comunidades Europeas de fecha 16 de junio de 1966, asunto 52-55/65, RFA \& C/Comisión; asunto C-14/68, Walt Wilhelm, de 13-2-1969); y del método de "el sistema y las finalidades" del Derecho derivado, la Sentencia del Tribunal de Justicia de las Comunidades Europeas, de fecha 17 de diciembre de 1970, asunto C-25/70, Köster, de 17-12-1970). Alguna fuente de interés sobre la consideración del preámbulo como parte integrante del texto convencional donde las partes expresen los fines y motivos del acuerdo, los principios jurídico-políticos y el marco jurídico general del mismo, en la práctica internacional, puede consultarse CORRIENTE CÓRDOBA, J. A., Valoración jurídica de los preámbulos de los tratados internacionales, Pamplona 1973. 
y objetivos de la norma objeto de examen, en principio, nos permitiría concluir que la norma sería aplicable a todas las distribuciones de beneficios y supuestos asimilados ${ }^{15}$ a este para evitar la doble imposición.

El significado de la expresión "distribución de beneficios" en la norma comunitaria objeto de estudio también podría determinarse mediante la concreción de aquellos supuestos expresamente excluidos por la norma y todos los que por su naturaleza jurídica no puedan subsumirse en la definición. A excepción del supuesto de reparto de beneficios derivados de la liquidación de la sociedad prevista en el artículo $4.1^{16}$, la norma no menciona expresamente la exclusión de ningún otro caso asimilado a la distribución de beneficios. Los supuestos de hecho más lógicos encadenados en esta expresión son los dividendos distribuidos por los entes societarios comprendidos en el ámbito subjetivo de esta norma.

Por un lado, el artículo 4 de la Directiva 2011/96/UE dispone expresamente que se aplicarán las medidas contenidas en dicho precepto para evitar la doble imposición internacional económica a la sociedad matriz o establecimiento permanente de esta que reciban por la participación en una sociedad filial de la primera "beneficios distribuidos por motivos distintos de la liquidación de la misma". De ello, puede concluirse que aquella distribución de beneficios derivados de la liquidación de la sociedad filial que los distribuye no podrán acogerse a los beneficios de la norma comunitaria.

Otra problemática añadida es que la norma tampoco define qué debe entenderse por "distribución de beneficios derivados de la liquidación de una sociedad", ni ofrece ningún supuesto de hecho que pudiera incardinarse dentro de dicha expresión. Con lo cual, en principio, el contribuyente deberá excluir la aplicación de la Directiva 2011/96/UE en aquellos casos en que se reciben beneficios derivados de la liquidación de la sociedad filial radicada en otro país miembro de la Unión Europea donde se han llevado a cabo el

${ }^{15}$ CALDERÓN CARRERO, J. M., y MARTIN JIMÉNEZ, A., «La Directiva relativa al sistema común de imposición aplicable en el caso de sociedades matrices y filiales de diferentes Estados miembros», en Convenios Fiscales Internacionales y Fiscalidad de la Unión Europea, Valencia 2010, p. 1090 // pp. 1077-1121. Estos autores postulan que el artículo 4.1 de la norma comunitaria presenta un concepto de "distribución de beneficios" restringido, frente al previsto en el artículo 5 que tendría un significado más amplio llegando a comprender los beneficios derivados de la liquidación de sociedades.

${ }^{16}$ RUIZ HIDALGO, C., Tributación de la empresa en la Unión Europea, Madrid-Barcelona 2002, p. 75. La autora entiende que la exclusión de este supuesto obedece a una prevención antifraude para evitar la posible participación en sociedades que corran un peligro real y evidente de posible disolución, y posterior liquidación, con ánimo de evitar la imposición a la que se sometería en el país de la sociedad filial. 
cumplimiento de todos los requisitos legalmente exigidos para la disolución $\mathrm{y}$ liquidación de dicha entidad ${ }^{17}$.

Por su parte, el artículo 7.2 de la Directiva 2011/96/UE establece que la norma no afectará a las disposiciones nacionales o convencionales que preveían el pago de créditos fiscales a los beneficiarios de "dividendos". Así, la Directiva 2011/96/UE realiza un mandato expreso en el que permite su aplicación a aquellos supuestos en que el contribuyente pueda verse beneficiado por el pago de un crédito fiscal en condiciones más beneficiosas de las que resultaría mediante la aplicación de esta norma. Los "beneficiarios de dividendos" erigen la fuente principal (pero no la única) de las transacciones intracomunitarias objeto de la presente norma en tanto en cuanto los "dividendos" representan la categoría de beneficios distribuidos por antonomasia realizado por las sociedades a sus accionistas o partícipes.

En íntima conexión con lo anterior, la expresión "distribución de beneficios" comprenderá todos aquellos beneficios que por su naturaleza jurídica o económica sean objeto de distribución a sus accionistas o partícipes con motivo de su participación en el capital de una entidad; y, a la vez, no supongan ningún tipo de contraprestación, directa o indirecta, por ninguna de las partes derivadas de las transacciones nacionales o internacionales realizadas dentro del grupo societario. Esta acepción podría equipararse a la expuesta en el Modelo de Convenio de la OCDE donde, tras hacer una equiparación de los dividendos a la distribución de beneficios en las observaciones preliminares al artículo 10 , el apartado 3 de dicho precepto establece que "El término "dividendos", en el sentido de este artículo, significa las rentas de las acciones, de las acciones o bonos de disfrute, de las participaciones mineras, de las partes de fundador $u$ otros derechos, excepto los de crédito, que permitan participar en los beneficios, asi como las rentas de otras participaciones sociales sujetas al mismo régimen fiscal que las rentas de las acciones por la legislación del Estado de residencia de la sociedad que hace la distribución» ${ }^{18}$.

La definición anteriormente expuesta podría resultar aplicable en el marco del artículo 4.1 de la Directiva pudiendo ampliarse su ámbito material, a los efectos de lo previsto en el artículo 5 de la misma norma a los supuestos de

17 La Ley 27/2014, de 27 de noviembre, del Impuesto sobre Sociedades española define solamente en dos preceptos, a saber, artículos 21.2 y 32.2 , lo que se entiende por dividendos, a los efectos de aplicar medidas para evitar la doble imposición; esencialmente, los derivados de los valores representativos del capital o de los fondos propios de entidades, con independencia de su consideración contable; las retribuciones correspondientes a préstamos participativos.

${ }^{18}$ OCDE, Model Tax Convention on Income and on Capital: Condensed Version 2017. París 2017, pp. 231 y siguientes. 
liquidación de sociedades, comprendiendo dicha norma un ámbito objetivo asimétrico $^{19}$.

En la Sentencia del Tribunal de Justicia de las Comunidades Europeas, asunto C-58/01, Océ van der Grinten NV, de 25-9-2003, se establecieron varias características generales definidoras de la distribución de beneficios, a saber: a) debe tratarse de cualquier rendimiento derivado de un título; b) el rendimiento debe obtenerse como consecuencia de la participación en el capital de la entidad filial; y c) la distribución del beneficio conllevaría una disminución del valor de la participación en el capital de la sociedad filial ${ }^{20}$.

Las sombras que pudieran presentarse al interpretar y aplicar la Directiva 2011/96/UE con las expresiones "beneficios distribuidos por motivos distintos de la liquidación de la misma" y/o "distribución de beneficios derivados de la liquidación de una sociedad", deberán colmarse mediante la remisión a lo previsto en los diferentes sistemas jurídicos tributarios de los Estados miembros en el mercado interior europeo, lo cual puede generar distorsiones, discriminaciones y ausencia de neutralidad fiscal por la deslocalización de capitales que podría tener lugar en función de la laxitud o restricción de la normativa tributaria de cada país europeo; así como también mediante lo estipulado en los convenios de doble imposición que no siempre ha tenido buena acogida en la doctrina ${ }^{21}$. En coherencia con esta línea de pensamiento, García Prats ${ }^{22}$ plantea una cuestión de gran relevancia referida al ámbito objetivo de la Directiva 2011/96/UE. En particular, centra el problema en la ausencia de unos mecanismos de vinculación de las rentas objeto de la norma comunitaria para los Estados miembros implicados en la distribución de beneficios transfronterizos del mercado interior europeo. Esto significa que podría darse el caso de que las rentas distribuidas por la sociedad filial de un país no sean consideradas de igual forma por el Estado miembro de la sociedad matriz. Como acertadamente apunta De La Cueva ${ }^{23}$, el concepto

${ }^{19}$ CALDERÓN CARRERO, J. M., y MARTÍN JIMÉNEZ, A., «La Directiva relativa al sistema común....cit., p. 1092».

${ }^{20}$ Aunque la sentencia ha sido objeto de estudio en el presente trabajo, las conclusiones expuestas sobre la definición de distribución de beneficios corresponden a GARCÍA PRATS, F. A., «La delimitación objetiva de las rentas afectadas por la Directiva 90/435/CEE: el concepto de beneficios distribuidos entre sociedades matrices y filiales», en Noticias de la Unión Europea (Valencia), 251 (2005) 91-121.

${ }^{21}$ GARCÍA PRATS, F. A., «La delimitación objetiva de las rentas...cit., 116». FABRA VALLS, M., «Contraste entre la Directiva sobre matrices y filiales y las medidas para evitar la doble imposición económica por dividendos en el Impuesto sobre Sociedades español», en Noticias de la Unión Europea (Valencia), 244 (2005) 74.

${ }^{22}$ GARCÍA PRATS, F. A., «La delimitación objetiva de las rentas...cit., 111 y 113 y siguientes».

${ }^{23}$ DE LA CUEVA GONZÁLEZ-COTERA, A., «La eliminación de la doble imposición cit., p. 68». 
de dividendo es diferente en cada Estado miembro pudiendo ser ganancia patrimonial en un país, renta del trabajo en otro y dividendo en otra jurisdicción fiscal europea. Luego, el significado y alcance de las expresiones "beneficios distribuidos por motivos distintos de la liquidación de la misma" y "distribución de beneficios derivados de la liquidación de una sociedad" al realizar la transposición de la Directiva 2011/96/UE por parte de los Estados miembros podría desembocar en disfuncionalidades mediante nociones distintas en las normas jurídico-tributarias de cada uno de los países comunitarios erigiendo una fuente de distorsiones, discriminaciones y ausencia de neutralidad fiscal quebrantando los objetivos y fundamentos de la norma comunitaria. No cabe duda de que esta indeterminación genera incertidumbre al contribuyente ${ }^{24}$.

Otro de los instrumentos jurídicos de que puede valerse el contribuyente para intentar contar con mayor seguridad jurídica en la aplicación de Directiva 2011/96/UE sería la casuística que vaya emanando de la jurisprudencia comunitaria, lo cual requerirá un examen meticuloso de las diferentes circunstancias que rodean cada caso concreto para poder concluir con nitidez la posibilidad de aplicar o no la norma comunitaria al supuesto en cuestión. Y también lo estipulado en los convenios de doble imposición y los comentarios al Modelo de Convenio de la OCDE.

Por ende, a nuestro modesto entender, las consideraciones anteriores ponen de manifiesto la necesidad de subsanar la presente norma ofreciendo una definición de lo que debe entenderse por "distribución de beneficios" o "beneficios distribuidos", "dividendos" y "distribución de beneficios derivados de la liquidación de una sociedad" por la exigencia lógica de una aplicación uniforme de la Directiva 2011/96/UE ${ }^{25}$. Todo ello, en aras de reforzar el principio de seguridad jurídica ${ }^{26}$ y soslayar conflictos judiciales innecesarios

${ }^{24}$ En el mismo sentido, RIBES, RIBES, A., La transposición de la Directiva 90/435/CEE (modificada por la Directiva 2003/123/CE) en el impuesto sobre la Renta de No Residentes y diferencias con los Convenios para evitar la doble imposición internacional. Noticias de la Unión Europea, 244 (2005) 101.

${ }^{25}$ En la misma línea de pensamiento, RIBES, RIBES, A. cit., p. 101. SÁNCHEZ JIMÉNEZ, Mª A., La doble imposición ...cit., p. 200. GARCÍA PRATS, F. A., $<<$ La delimitación objetiva de las rentas...cit., 91 y siguientes. Vid. el estudio realizado por este autor sobre el concepto comunitario de distribución de beneficios intentando colmar la laguna que nos deja la Directiva 2011/96/UE. Para ello, se vale de tres opciones, a saber: 1) completar la definición de la referencia al Derecho comunitario derivado de sociedades; 2) mediante remisión al Derecho tributario interno de los países comunitarios; 3) mediante el estudio de las exigencias que pueden desprenderse de la Directiva 2011/96/UE, atendiendo a sus exclusiones, objetivos y finalidades.

${ }^{26}$ Sentencias del Tribunal Europeo de Derechos Humanos, caso Sunday Times, § 49, 26-41979; caso Silver, de 25-3-1983; caso Malone, 2-8-1984; caso Kruslin y Huvig, de 24-4-1990; caso Valenzuela, de 30-7-1998; caso Rekveny, de 20-5-1999; caso Hashman y Harrup, de 25-11-1999; caso Amann, de 16-2-2000; caso Rotaru, de 4-5-2000; Sentencias del Tribunal de Justicia de 
que siempre irán en detrimento del contribuyente (y del erario público, a medio o largo plazo) por diferentes canales, así como de los objetivos y fundamentos de la propia Directiva 2011/96/UE para evitar la doble imposición jurídica y la económica.

\subsection{Supuestos de doble imposición}

El primer supuesto de hecho comprendido dentro del ámbito objetivo de la Directiva 2011/96/UE se refiere a las distribuciones de beneficios recibidos por las sociedades de un Estado miembro y procedentes de sus filiales situadas en otros países de la Unión Europea. A título ejemplificativo, el supuesto clásico referido en este caso comprendería la distribución de dividendos de una sociedad filial F radicada en Alemania a su sociedad matriz M, receptora de los mismos, residente en España. Los fenómenos de doble imposición que pueden producirse en este caso comprenden tanto la doble imposición jurídica ${ }^{27}$ como la doble imposición internacional económica. Luego, las medidas para evitar o eliminar la doble imposición previstas en la Directiva 2011/96/UE (que serán examinadas, posteriormente) aborda los supuestos clásicos de doble imposición que no siempre han podido solventarse a través de los convenios de doble imposición donde suele contemplarse la retención en el país de la fuente con las limitaciones establecidas en cada tratado o el método de la imputación limitada en la fracción de impuesto satisfecho por el contribuyente en el extranjero.

El segundo supuesto de hecho contemplado en el artículo 1 de la Directiva 2011/96/UE comprende la inversa del anterior, es decir las distribuciones de beneficios realizadas por las sociedades matrices residentes en un Estado miembro a sus filiales situadas en otros países miembros de la Unión Europea. El apartado c) del artículo 1 de la Directiva 2011/96/UE incluye en el ámbito de aplicación de la norma el caso de las distribuciones de beneficios recibidos por establecimientos permanentes situados en un Estado miembro que pertenecen a sociedades radicadas en otros Estados miembros de la Unión Europea. Ésos beneficios distribuidos deben proceder de filiales de aquella sociedad situados en un Estado miembro distinto del establecimiento permanente. Y el

\footnotetext{
las Comunidades Europeas, C-17/03, VEMW, , de 7-6-2005; asunto C-362/12, Test Claimants in the Franked Investment Income Group Litigation / Commissioners of Inland Revenue y Commissioners for Her Majesty's Revenue and Customs, de 12-12-2013; en el ordenamiento jurídico español, entre las incontables resoluciones, al respecto: Sentencias del Tribunal Constitucional 27/1981, de 20 de Julio; 65/1990, de 5 de abril; 150/1990, 4 de octubre; 46/1990, de 15 de marzo.

${ }^{27}$ Nos referiremos a ella indistintamente como doble imposición internacional, doble imposición internacional jurídica o doble imposición jurídica.
} 
último supuesto previsto en esta norma es similar al anterior con la matización de que, además, este último caso contempla aquel en que la distribución de beneficios por parte de la sociedad filial de otra, ambas residentes en el mismo Estado miembro, que distribuye beneficios a un establecimiento permanente situado en otro país comunitario.

Huelga comentar que los supuestos contemplados en el precepto examinado deberán interpretarse en sentido amplio no sólo por la complejidad con que las operaciones de distribuciones de beneficios y transacciones análogas se presentan en el plano económico internacional de las empresas sino por los fundamentos y objetivos perseguidos por la Directiva 2011/96/UE que tratan de evitar distorsiones, restricciones, desventajas y discriminaciones en la creación, ampliación y consolidación de los grupos societarios europeos.

\subsection{Límites al ámbito de aplicación de la Directiva 2011/96/UE. La cláusula anti-abuso}

En ocasiones, las planificaciones y transacciones económicas de los grupos empresariales transnacionales pueden perseguir fines evasivos al erario público del país o países imbricados en dicha operativa. Ésas estrategias se traducen en un complejo y conglomerado tejido empresarial deslocalizado en diferentes jurisdicciones fiscales frente a los cuales, las soberanías fiscales intentan protegerse mediante diversidad de herramientas jurídicas, como las presunciones iuris et de iure, limitaciones interpretativas, normas restrictivas, etc.

Sin embargo, no debe olvidarse que el objetivo esencial de la Directiva 2011/96/UE consiste en facilitar la integración y ampliación de los grupos societarios europeos mediante la eliminación de cualquier penalización, entre la que se presta especial atención al fenómeno de la doble imposición económica en la distribución de beneficios de los grupos de sociedades y la doble imposición jurídica mediante la eliminación de la retención en origen, así como cualquier otra exacción análoga. Por ello, a nuestro modesto entender, no sería admisible la aplicación de una norma jurídico-tributaria nacional o convencional que so pretexto de un presunto propósito, práctica fraudulenta o evasiva carente de concreción y/o justificación se limitara a denegar los beneficios de la Directiva fiscal europea produciendo el fenómeno de la doble imposición en un supuesto para el que dicha norma previera su eliminación.

La inaplicación de la Directiva 2011/96/UE en los términos expuestos en el artículo $1.2^{28}$ y sus nuevos apartados 3 y 4 , deberá tener carácter restrictivo,

${ }^{28}$ La Directiva (UE) 2015/121, del Consejo, de 27 de enero modificó el artículo 1.2 de dicho precepto, introduciendo dos nuevos apartados, en los siguientes términos: ”2. Los Estados 
ser preciso (Sentencia del Tribunal de Justicia de las Comunidades Europeas, asunto C-255/02 Halifax \& Leeds Permanent Development Services Ltd plc, de fecha 21-2-2006, apartado 72) ${ }^{29}$, examinando cada caso concreto (Sentencia del Tribunal de Justicia de las Comunidades Europeas, asunto C-196/04 Cadbury Schweppes plc \& Cadbury Schweppes Overseas Ltd, de fecha 12-9-2006, apartados 37 y 38$)^{30}$, evitando que se transgredan las libertades de circulación que cimientan el mercado interior europeo ${ }^{31}$. Además, este carácter restrictivo debe estar rigurosamente justificado, caso por caso, sin que quepa la aplicación de meras presunciones o justificaciones abstractas que traten de privar de efectos la Directiva 2011/96/UE ${ }^{32}$, en todo o en parte, o introducir técnicas regulatorias que traten de compensar la pérdida recaudatoria (Sentencia del Tribunal de

miembros no acordarán los beneficios contemplados en la presente Directiva a un arreglo o una serie de arreglos falseados, vistos todos los hechos y circunstancias pertinentes, por haberse establecido teniendo como propósito principal o uno de sus propósitos principales la obtención de una ventaja fiscal que desvirtúe el objeto o la finalidad de la presente Directiva. Un arreglo podrá estar constituido por más de una fase o parte. 3. A efectos del apartado 2, un arreglo o una serie de arreglos se considerarán falseados en la medida en que no se hayan establecido por razones comerciales válidas que reflejen la realidad económica. 4. La presente Directiva no será obstáculo para la aplicación de disposiciones nacionales o convencionales que sean necesarias para la prevención de la evasión fiscal, el fraude fiscal o las prácticas abusivas".

29 "según ha recordado en reiteradas ocasiones el Tribunal de Justicia, la legislación comunitaria también debe ser precisa y su aplicación previsible para los justiciables (véase, en particular, la sentencia de 22 de noviembre de 2001, Países Bajos/Consejo, C-301/97, Rec. p. I8853, apartado 43). Este imperativo de seguridad jurídica se impone con especial rigor cuando se trata de una normativa que puede implicar consecuencias financieras, a fin de permitir que los interesados conozcan con exactitud el alcance de las obligaciones que se les imponen (véanse, en particular, las sentencias de 15 de diciembre de 1987, Países Bajos/Comisión, 326/85, Rec. p. 5091, apartado 24, y de 29 de abril de 2004, Sudholz, C-17/01, Rec. p. i-4243, apartado 34)".

30 "Por lo que se refiere a la libertad de establecimiento, el Tribunal de Justicia ha declarado ya que la circunstancia de que la sociedad se haya constituido en un Estado miembro con la finalidad de beneficiarse de una legislación más favorable no es, por si sola, suficiente para llegar a la conclusión de que existe un uso abusivo de dicha libertad (véanse, en este sentido, las sentencias Centros, antes citada, apartado 27, y de 30 de septiembre de 2003, Inspire Art, C-167/01, Rec. p. I10155, apartado 96)"; "De ello se deduce, como han señalado las demandantes en el asunto principal y el Gobierno belga así como, durante la vista, el Gobierno chipriota, la circunstancia de que CS haya decidido en este caso constituir CSTS y CSTI en el IFSC con la finalidad reconocida de beneficiarse del régimen fiscal favorable que proporciona tal establecimiento no constituye, en si misma, un abuso. Por consiguiente, esta circunstancia no excluye que CS pueda invocar los artículos 43 CE y 48 CE (véanse, en este sentido, las sentencias, antes citadas, Centros, apartado 18, e Inspire Art, apartado 98)".

${ }^{31}$ VARIOS, La armonización fiscal en la comunidad...cit., pp. 15-16. Se afirma que la importancia de la función que desarrollan estas libertades en orden a la consecución del mercado interior va más allá de un mercado sin fronteras interiores que hace que sus limitaciones sean interpretadas en sentido restrictivo por el aplicador del Derecho comunitario exigiendo un fundamento en el derecho positivo.

32 Del mismo parecer, LÓPEZ RODRÍGUEZ, J., «El concepto de beneficiario efectivo en la Directiva europea de intereses y cánones», en Revista de Contabilidad y Tributación (Madrid), 358 (2013) 41. 
Justicia de las Comunidades Europeas, asunto F.W.L. de Groot \& Staatssecretaris van Financiën, C-385/00, de fecha 12 de diciembre de 2002, apartado 103) $)^{33}$ por la aplicación de la norma comunitaria, ni tampoco generar distorsiones, restricciones, desventajas o discriminaciones que dificulten o desalienten las operaciones de distribución de beneficios realizadas en los grupos de sociedades que ampara y protege la Directiva 2011/96/UE ${ }^{34}$.

La Corte comunitaria ha esbozado una doctrina sobre el abusivo del Derecho comunitario en las Sentencias Cadbury Schweppes, Halifax y Centros Ltd. En el asunto C-196/04 Cadbury Schweppes plc \& Cadbury Schweppes Overseas Ltd, de fecha 12-9-2006. Así, el tribunal recordaba que "los nacionales de un Estado miembro no pueden, aprovechando las posibilidades creadas por el Tratado, intentar evitar abusivamente la aplicación de su legislación nacional Tampoco pueden invocar las normas comunitarias de forma abusiva of fraudulenta (sentencias de 7 de febrero de 1979, Knoors, 115/78, Rec. p. 399, apartado 25; de 3 de octubre de 1990, Bouchoucha, C-61/89, Rec. p. I-3551, apartado 14, $y$ de 9 de marzo de 1999, Centros, C-212/97, Rec. p. I-1459, apartado 24)" (apartado 35). Otra consideración importante que resaltó el tribunal en la sentencia reseñada era que "el hecho de que un nacional comunitario, persona fisica o jurídica, haya sacado provecho de las ventajas fiscales ofrecidas por las normas en vigor en un Estado miembro distinto de aquél en el que reside, no autoriza, por sí solo, a privarle de la posibilidad de invocar disposiciones del Tratado (véase, en este sentido, la sentencia de 11 de diciembre de 2003, Barbier, C-364/01, Rec. p. I-15013, apartado 71)"35 (apartado 36); ni tampoco puede invocarse una presunción general de fraude fiscal ni servir de justificación

33 "hay que recordar la jurisprudencia reiterada según la cual la pérdida de ingresos fiscales nunca puede justificar una restricción al ejercicio de una libertad fundamental (sentencia de 16 de julio de 1998, ICI, C-264/96, Rec. p. I-4695, apartado 28, y Saint-Gobain ZN, antes citada, apartado 51)".

${ }^{34}$ En la misma línea de pensamiento, CALDERÓN CARRERO, J. M., «Algunas consideraciones en torno a la interrelación entre los convenios de doble imposición y el Derecho comunitario europeo: ¿Hacia la "comunitarización de los CDIS”?», en Documentos (Madrid), 4/02 (2001) 18-19.

${ }^{35}$ El apartado 49 de esta sentencia recalcaba esa idea, cuando esgrimió: "es jurisprudencia reiterada que la existencia de una ventaja que se derive de una carga fiscal menor a la que esté sometida una filial establecida en un Estado miembro distinto de aquél en que se haya constituido la sociedad matriz no justifica, por si misma, que este último Estado miembro compense dicha ventaja con un trato fiscal menos favorable a la sociedad matriz (véase, en este sentido, la sentencia de 28 de enero de 1986, Comisión/Francia, 270/83, Rec. p. 273, apartado 21; véanse también, por analogía, las sentencias de 26 de octubre de 1999, Eurowings Luftverkehr, C-294/97, Rec. p. I-7447, apartado 44, así como de 26 de junio de 2003, Skandia y Ramstedt, C-422/01, Rec. p. I-6817, apartado 52). La necesidad de prevenir la reducción de ingresos fiscales no figura ni entre los objetivos mencionados en el artículo $46 C E$, apartado 1 , ni entre las razones imperiosas de interés general que pueden justificar la restricción de una libertad consagrada en el Tratado (véanse, en este sentido, las sentencias de 3 de octubre de 2002, Danner, C-136/00, Rec. p. I8147, apartado 56, asi como Skandia y Ramstedt, antes citada, apartado 53)”. 
una medida que coarte una libertad fundamental, por el simple hecho de que un contribuyente haya abierto un establecimiento secundario en otro país comunitario (apartado 50). Además, el tribunal exigió la debida proporcionalidad y razones imperiosas de interés general en la adopción de las medidas adoptadas que puedan suponer una restricción a las libertades fundamentales ${ }^{36} \mathrm{del}$ mercado interior europeo (apartado 47), salvo que se trate de montajes puramente artificiales cuyo objeto sea eludir la aplicación de la legislación del Estado miembro en cuestión (apartado 51). La Corte europea citó un supuesto que entraría dentro de la casuística del abuso en la aplicación del Derecho comunitario, en particular, "la sentencia Marks \& Spencer, antes citada, que consisten en organizar transferencias de pérdidas, dentro de un grupo de sociedades, a sociedades establecidas en los Estados miembros que apliquen los tipos impositivos más elevados y donde, en consecuencia, el valor fiscal de dichas pérdidas sea mayor, el tipo de comportamientos descritos en el apartado anterior puede menoscabar el derecho de los Estados miembros a ejercer su competencia fiscal en relación con las actividades realizadas en su territorio y poner de este modo en peligro el equilibrio en el reparto de la potestad tributaria entre los Estados miembros (véase la sentencia Marks \& Spencer, antes citada, apartado 46)" (apartado 52). Todas estas postulaciones jurisprudenciales vienen a reiterar las esgrimidas previamente por el tribunal en la Sentencia Halifax, referida a la Sexta Directiva sobre el Impuesto sobre el Valor Añadido. En la Sentencia del Tribunal de Justicia de las Comunidades Europeas, asunto C-212/97, Centros Ltd \& Erhvervs- og Selskabsstyrelsen, de fecha 9 de marzo de 1999. Además de las consideraciones expuestas, estableció los requisitos sobre las medidas adoptadas por los países comunitarios para evitar prácticas abusivas en la aplicación del Derecho comunitario, a saber, "según la jurisprudencia del Tribunal de Justicia, las medidas nacionales que puedan obstaculizar o hacer menos atractivo el ejercicio de las libertades fundamentales garantizadas por el Tratado deben reunir cuatro requisitos: que se apliquen de manera no discriminatoria, que estén justificadas por razones imperiosas de interés general, que sean adecuadas para garantizar la realización del objetivo que persiguen y que no vayan más allá de lo necesario para alcanzar dicho objetivo (véanse las sentencias de 31 de marzo de 1993, Kraus, C-19/92, Rec. p. I-1663, apartado 32, y de 30 de noviembre de 1995, Gebhard, C-55/94, Rec. p. I-4165, apartado 37)" (apartado 34).

De la jurisprudencia comunitaria expuesta, Calderón ${ }^{37}$ clasifica los requisitos objetivos, subjetivos y procesales que los Estados miembros deben aplicar, cuando adoptan medidas anti-abuso del Derecho comunitario, a saber: a) requisito

\footnotetext{
${ }^{36}$ En el caso particular, se refería a la libertad de establecimiento.

${ }^{37}$ CALDERÓN CARRERO, J. M., «Algunas consideraciones en torno...cit., pp. 18-19».
} 
objetivo: constatar que se trata de una práctica abusiva en el que no se ha alcanzado el objetivo perseguido por la norma comunitaria; b) requisito subjetivo: se requiere la voluntad de obtener un beneficio resultante de la normativa comunitaria, creando artificialmente las condiciones exigidas para su obtención; c) requisitos procesales: las autoridades deben acreditar la existencia de estos dos elementos, conforme a las normas del Derecho nacional, siempre que ello no vulnere la eficacia del Derecho comunitario. Luego, continúa el autor afirmando la necesidad de que las medidas adoptadas por los Estados miembros, a tal fin, deben cumplir cuatro condiciones: a) Que no sean discriminatorias; b) Que persigan un fin legítimo; c) Sean adecuadas a tal fin; d) fueran proporcionadas no yendo más allá de lo necesario ni menoscabar la esencia del derecho conferido por el ordenamiento comunitario; e) en algún caso, el Tribunal de Justicia de las Comunidades Europeas también ha esgrimido que las medidas nacionales no deben vulnerar los derechos fundamentales de los nacionales afectados (casos Gloszczuk, C-63/99, y 235/99, ambas de 27 de septiembre de 2001).

Por ende, el artículo 1.2, 1.3 y 1.4 de la Directiva 2011/96/UE no deben erigir un instrumento para que los Estados miembros soslayen la aplicación de las medidas para evitar la doble imposición contenidas en las normas comunitarias debiendo analizar cada caso concreto, asumiendo la carga de la prueba y justificación del propósito y objetivo de cada transacción con criterios objetivos, proporcionados y no discriminatorios. Los contribuyentes que se vieran afectados por la aplicación de disposiciones nacionales o convencionales carentes de justificación alguna y/o, en su caso, con la inaplicación de los beneficios contenidos en la norma comunitaria, además de los recursos previstos en los ordenamientos jurídicos internos de los países comunitarios, y la posibilidad de solicitar el planteamiento cuestiones prejudiciales (ex. artículo 267 del Tratado de Funcionamiento de la Unión Europea), podría solicitar la suspensión de la eficacia de dichas disposiciones mediante la tutela cautelar, si se cumplen dos condicionantes. El primero, la apariencia de buen derecho o fumus boni iuris, esto es que el derecho invocado por el contribuyente parezca probable y jurídicamente aceptable; y el segundo, el periculum in mora o riesgo de ineficacia de la resolución judicial ante el perjuicio grave e irreparable que podría producirse hasta la resolución judicial definitiva ${ }^{38}$. Todo lo anterior, además de los posteriores recursos jurisdiccionales ante al Tribunal de Justicia de la Unión Europea (ex. artículos 256 y siguientes).

${ }^{38}$ MANGAS MARTÍN, A., y LIÑÁN NOGUERAS, D. J., Instituciones y derecho de la Unión europea. Madrid 2016, pp. 447-450. Los autores citan las Sentencias del Tribunal de Justicia de las Comunidades Europeas, asunto Factortame, C-213/89, de fecha 19 de junio de 1990; asunto Factortame II, C-221/89, de fecha 25 de julio de 1991; asunto Comisión c. Reino Unido, C-246/89; asunto Simmenthal de 1978; asuntos Ariete 811/79 y Mireco 826/79, de fecha 10 de julio de 1980 . 


\section{III. ÁMBITO SUBJETIVO DE LA DIRECTIVA 2011/96/UE Y LA DOBLE IMPOSICIÓN}

El ámbito subjetivo de la norma fiscal comunitaria relaciona los sujetos pasivos del impuesto sobre sociedades en los diferentes Estados miembros de la Unión Europea. El artículo 2 de la Directiva 2011/96/UE determina el ámbito subjetivo de la norma mediante la definición de lo que debe entenderse por "sociedad de un Estado miembro" y por "establecimiento permanente".

\subsection{Definición de sociedad y presupuestos materiales para evitar la doble} imposición

La norma comunitaria exige la concurrencia de tres requisitos, al definir "sociedad de un Estado miembro". El primero requiere que comprenda alguna de las entidades enumeradas en la parte A del anexo I de la Directiva 2011/96/UE. Por un lado, dicho anexo contempla las sociedades constituidas al amparo de lo dispuesto en el Reglamento (CE) $n .^{\circ}$ 2157/2001 del Consejo, de 8 de octubre de 2001, por el que se aprueba el Estatuto de la Sociedad Anónima Europea (SE), y la Directiva 2001/86/CE del Consejo, de 8 de octubre de 2001, por la que se completa el Estatuto de la Sociedad Anónima Europea en lo que respecta a la implicación de los trabajadores, y las sociedades cooperativas incorporadas en virtud del Reglamento (CE) n. ${ }^{\circ} 1435 / 2003$ del Consejo, de 22 de julio de 2003, relativo al Estatuto de la Sociedad Cooperativa Europea (SCE), y la Directiva 2003/72/CE del Consejo, de 22 de julio de 2003, por la que se completa el Estatuto de la Sociedad Cooperativa Europea en lo que respecta a la implicación de los trabajadores.

Por otro lado, el anexo I de la Directiva fiscal europea realiza una exposición de las distintas corporaciones jurídicas previstas en cada uno de los Estados miembros. Dentro de esta clasificación, se observa que algunos países, como es el caso de España, tras hacer mención a las diferentes modalidades societarias, realiza una remisión genérica a "Otras entidades constituidas con arreglo al Derecho español sujetas al impuesto sobre sociedades español". Ello nos permitiría afirmar que, siempre que concurran el resto de requisitos exigidos para la definición "sociedad de un Estado miembro", todos los sujetos pasivos del impuesto sobre sociedades español podrán beneficiarse de la aplicación de la Directiva 2011/96/UE; y, en consecuencia, podrán evitar tanto la doble imposición jurídica como la doble imposición internacional económica sobre la distribución de beneficios ${ }^{39}$.

${ }^{39}$ Piénsese en el ejemplo de una fundación F, residente en España, que participa al 15\% una sociedad S, residente en Italia. A su vez, la sociedad matriz M, residente en España, 
Siguiendo la clasificación de entidades corporativas relacionadas en la parte A del anexo I de la Directiva 2011/96/UE, a diferencia del caso de España, encontramos clasificaciones restrictivas de las sociedades comprendidas en el ámbito de la norma comunitaria por parte de algunos países miembros. Un ejemplo lo apreciamos en el apartado o) de dicho anexo I, referida a las sociedades constituidas con arreglo al Derecho lituano donde se realiza una simple mención a "las sociedades constituidas con arreglo al Derecho lituano". En este caso, no se hace alusión a todos los entes sujetos al impuesto de sociedades lituano sino a las sociedades constituidas con arreglo al derecho de aquella jurisdicción. En coherencia con este planteamiento, Calderón y Martín ${ }^{40}$ postulan otras asimetrías como la sociedad civil española y la portuguesa o los conceptos de sociedad de Bélgica, Alemania, Grecia, España, Francia, Luxemburgo, Holanda y Austria, respecto a Reino Unido, Portugal o Italia, así como a la dicotomía entre cualquier ente sujeto pasivo del impuesto sobre sociedades y el imperativo estatus de sociedad constituida, conforme a las normas de los Estados miembros.

A nuestro humilde parecer, las reflexiones anteriores ponen de manifiesto que resultaría menester ampliar el concepto de sociedad a todas las entidades que fueran sujeto pasivo del impuesto sobre sociedades en todos los Estados miembros descartando las restricciones en la determinación de tal concepto. Todo esto, en aras de soslayar discriminaciones fiscales sobre las mismas rentas comunitarias, según se trate de un tipo de corporación u otra, aunque tributen por el mismo impuesto de sociedades; distorsiones en la localización de capitales motivada por este tipo de restricciones; y desventajas y ausencia de neutralidad fiscal en tal sentido dentro del mercado interior europeo ${ }^{41}$. En

participa la sociedad S al 20\%. Pues bien, en tal caso, no solamente será la sociedad matriz M la que podrá invocar la aplicación de la Directiva 2011/96/UE para evitar la doble imposición sino que también podrá instarlo la fundación $\mathrm{F}$ al tratarse de un ente que es sujeto pasivo del impuesto sobre sociedades español. Si bien, no cabría aplicar la norma comunitaria a las fundaciones españolas acogidas a la Ley 49/2002, de 23 de diciembre, de régimen fiscal de las entidades sin fines lucrativos y de los incentivos fiscales al mecenazgo, (artículos 6 y 7), al tratarse de entidades sujetas y exentas, como se estudiará en páginas posteriores.

${ }^{40}$ CALDERÓN CARRERO, J. M., y MARTÍN JIMÉNEZ, A., $<<$ La Directiva relativa al sistema común... cit., pp. 1078-1080.

${ }^{41}$ Aunque el objeto del presente trabajo se centra en la tributación de las rentas societarias, cabría apuntar, con carácter meramente complementario, la conveniencia de extender el ámbito subjetivo de la Directiva 2011/96/UE a los empresarios individuales que operan en el mercado interior europeo en tanto en cuanto éstos no compiten en igualdad de condiciones con los grupos societarios comunitarios al no poderse beneficiar de las medidas contenidas en dicha norma para evitar la doble imposición internacional teniendo que conformarse con las medidas de Derecho tributario internacional contenidas en la legislación doméstica de cada uno de los países miembros comunitarios y en los convenios bilaterales para evitar la doble imposición. De hecho, sin ánimo de extendernos en esta cuestión, la Comisión ya se hizo eco de esta cuestión 
definitiva, se trataría de evitar las nocivas consecuencias derivadas de la producción de supuestos de doble imposición jurídica y doble imposición internacional económica para muchas entidades no incluidas en el concepto de sociedad recogido en la parte A del anexo I de dicha norma.

El segundo requisito concurrente que exige el artículo 2 de la Directiva 2011/96/UE es que la sociedad tenga su domicilio fiscal en un Estado miembro de la Unión Europea, con arreglo a lo previsto en la legislación doméstica del país comunitario ${ }^{42}$ en cuestión; $y$, además, que, en virtud de un convenio de doble imposición celebrado con un tercer Estado, no se considere que tiene su domicilio fiscal fuera del territorio comunitario. La Directiva 2011/96/UE no aporta ninguna definición homogénea de domicilio fiscal ni criterios de determinación del mismo, así como tampoco ofrece supuestos en los que deba prevalecer un caso u otro para solventar posibles conflictos de determinación del domicilio fiscal entre dos o más países miembros de la Unión Europea, limitándose a delegar la cuestión a los convenios de doble imposición internacional suscritos entre los países miembros y terceros Estados.

A efectos de la Directiva 2011/96/UE, el "domicilio fiscal" parece referirse al hecho que las sociedades estén domiciliadas en un Estado miembro y que no sea considerada residente fiscal en un tercer Estado no comunitario. Luego, si una sociedad fuera considerada residente fiscal en un país extracomunitario, en virtud de lo dispuesto en un convenio de doble imposición firmado con un Estado miembro de la Unión Europea, la Directiva 2011/96/UE no resultaría aplicable. Con lo cual, la norma comunitaria se abstrae de los conflictos de doble residencia que pudieran suscitarse en los convenios de doble imposición dejando el problema en manos de las autoridades fiscales competentes a través del procedimiento amistoso o, en su caso, a lo que diriman las instancias judiciales nacionales.

en la COM (2003) 810 final. Participan del mismo parecer, DE LA MAZA GARCÍA, J., «Orientaciones de la Comisión sobre fiscalidad de las empresas en el ámbito del mercado interion», en Documentos (Madrid), (1992) 3. COMISIÓN DE LAS COMUNIDADES EUROPEAS, «Communication de la Commission au Conseil et au Parlement Europeen consecutive aux conclusions du Comité de reflexión preside par O. Ruding et portant sur les orientations en matiere de fiscalité des entreprises daus le cadre de l'approfondissement du marché intérieur», en SEC (Bruselas) 92 (1992) 1118 final 252. RUDING, «Informe del Comité Ruding...cit., 224». LÓPEZ ESPADAFOR, C. M., «Consi-deraciones sobre neutralidad fiscal en el ámbito empresarial», en Revista de Contabilidad y Tributación (Madrid), 262 (2005) 85.

42 Sobre la domiciliación de la sociedad matriz en el ámbito de la Unión Europea, es de especial interés consultar la Sentencia del Tribunal Supremo español, de fecha 22 de marzo de 2012, referida $a$ una filial holandesa ubicada en territorio español, participada al $100 \%$ por su matriz holandesa, participada ésta última por otra corporación en Holanda, y ésta última por otra entidad de Estados Unidos, y el dictamen de la Comisión, Caso 2005/2275, al respecto. También, en un supuesto similar, la SG de Tributación de no Residentes de España, $n^{\circ}$ consulta 0262-02, de fecha 19-02-2002. 
La exigencia del requisito del "domicilio fiscal" unido a la omisión de un criterio que lo defina (y de criterios para solventar los conflictos de doble residencia), a efectos de aplicación de la Directiva comunitaria, tiene una significación relevante fundamentalmente para aquellos grupos de sociedades multinacionales que operan dentro y fuera del mercado interior europeo. No obstante, esta cuestión podría ser integrada mediante la aplicación el artículo 4 del Modelo de Convenio de la $\mathrm{OCDE}^{43}$ que prevé unos criterios, en virtud de los cuales se entiende que una persona física o jurídica es residente fiscal o no en un país u otro ofreciendo un elenco de definiciones y supuestos en la redacción del precepto para evitar que se produzca la doble imposición internacional por dualidad de residencia y proliferen litigios fiscales, en aras de que el contribuyente pueda lograr la mayor seguridad jurídica posible ${ }^{44}$. Lo cual colmaría esta deficiencia con una proyección multilateral frente a la bilateralidad de los convenios de doble imposición.

En definitiva, partiendo de lo expuesto anteriormente, en el sentido de que si los Estados miembros han aceptado el Modelo de Convenio de la OCDE y sus comentarios ${ }^{45}$, a la vez que han suscrito numerosos convenios de doble imposición extrapolando dicho precepto y sus comentarios interpretativos, no parecería excesivo intentar ofrecer una definición o criterio esencial de lo que debe entenderse por "domicilio fiscal" o, en su caso, señalar los instrumentos jurídicos del Modelo de Convenio de la OCDE como fuente subsidiaria, en defecto de la norma comunitaria. Esto sería así en tanto en cuanto tal deficiencia puede presentarse, a nuestro modesto entender, como una de las cuestiones controvertidas para resolver algunos conflictos que pudieran plantearse en tal sentido. Esta omisión, que también podría calificarse de pasividad, podría abrir la puerta a supuestos de doble imposición internacional.

El tercer requisito que exige el artículo 2 de la Directiva 2011/96/UE para calificar a las corporaciones como "sociedad de un Estado miembro" es que estén sujetas y no exentas a uno de los impuestos relacionados en la parte B

${ }^{43}$ OCDE, Model Tax Convention...cit., pp. 30 y 105 y siguientes.

${ }^{44}$ CALDERÓN CARRERO, J. M., y MARTÍN JIMÉNEZ, A., «La Directiva relativa al sistema común... cit., p. 1081». Calderón señala algunos supuestos, en los que entiende que podría aplicarse la norma comunitaria en casos de doble residencia, por ejemplo, cuando no mediara convenio de doble imposición entre el Estado miembro afectado por la aplicación de la Directiva y el tercer Estado donde se considere domiciliada la empresa, o, cuando la empresa tenga doble residencia fiscal en dos Estados miembros, los cuales, en virtud de un convenio de doble imposición atribuyen la residencia en tanto en cuanto postulan que la Directiva no exige que los requisito deban cumplirse necesariamente en el mismo Estado.

${ }^{45}$ Hacemos abstracción de las observaciones o reservas que algunos hayan podido realizar a dicho precepto, como es el caso de las observaciones formuladas por España y Hungría y las reservas realizadas por Francia, Portugal y Suecia. 
del anexo $I^{46}$ de dicha norma o cualquier otro impuesto análogo de la misma naturaleza. La sujeción impositiva requerida debe ser imperativa y no opcional. Luego, la exigencia de este tercer requisito se traduce en la obligación jurídico-tributaria de que las sociedades incluidas en el ámbito subjetivo de la Directiva 2011/96/UE tributen en el impuesto sobre sociedades del país comunitario en cuestión para poder aplicarse las medidas previstas en aquella para evitar la doble imposición jurídica y la doble imposición internacional económica. Quedando pues, fuera de su aplicación aquellas entidades no sujetas al impuesto de sociedades o corporaciones sujetas y exentas a dicho impuesto ${ }^{47}$, aunque no en aquellos casos de aplicación de tipos de gravamen muy inferiores a los exigidos con carácter general ${ }^{48}$. Es decir, se exige la sujeción y no exención de las sociedades y establecimientos permanentes que perciban beneficios distribuidos desde otras jurisdicciones comunitarias en las que se hubiera aplicado un tipo impositivo en el impuesto sobre sociedades inferior al que corresponde en el país de origen de la sociedad matriz.

Sin embargo, subyacen algunas cuestiones de matiz en la exigencia del requisito de la sujeción y la exención. Por un lado, cabe plantearse, si la sujeción parcial al impuesto sobre sociedades que viene a significar una exención o no sujeción parcial de dicho impuesto sería suficiente para entender que la sociedad está sujeta al impuesto; y, por consiguiente, puedan aplicarse las medidas contenidas en la Directiva 2011/96/UE para evitar la doble imposición jurídica y la doble imposición internacional económica. $\mathrm{O}$, si por el contrario, la sujeción debe ser total, con arreglo a la estructura del impuesto. A nuestro modesto entender, una interpretación sistemática de los objetivos y fundamentos de la norma junto a la imprecisión del precepto reseñado permitiría concluir que la norma será aplicable a aquellas entidades sujetas parcialmente al impuesto sobre sociedades ${ }^{49}$. Esto es así porque dicho

${ }^{46}$ Dicho anexo se limita a exponer los impuestos sobre sociedades de los diferentes países miembros de la Unión Europea.

${ }^{47}$ RIBES, RIBES, A. (2005), cit., p. 103. La autora cita una Resolución de la Dirección General de Tributos, de fecha 16 de julio de 1992 y otra, de fecha 27 de octubre de 1994 que participan del mismo parecer. Ello, sin obviar la necesidad de analizar cada caso concreto, como se pone de manifiesto en la Resoluciones, de fecha 2 de junio y 22 de julio de 1999 (citadas también en esta obra) donde se esgrime "[...] Se trata más bien, de comparar en cada caso, [...] de manera que ambos no difieran de manera sensible y por causas que resultarian extrañas a la estructura básica de nuestro impuesto sobre sociedades".

${ }^{48}$ RUIZ HIDALGO, C., Tributación... cit., p. 73. Por ello, discrepamos con la autora, cuando afirma que, además de no ser aplicable la norma comunitaria a los regímenes fiscales privilegiados como puede ser una exención total (con lo que coincidimos), tampoco resultaría aplicable en aquellos casos de aplicación de tipos de gravamen muy inferiores a los exigidos con carácter general.

${ }^{49}$ En cualquier caso, las precisiones necesarias para arrojar luz sobre la cuestión planteada debería solventarse dentro del marco de la propia Directiva 2011/96/UE soslayando delegar esta potestad a los Estados miembros. 
impuesto puede presentar diferentes regímenes con un tratamiento jurídicotributario dispar ${ }^{50}$.

En conclusión, puede afirmarse que la sujeción total o parcial al impuesto sobre sociedades cumpliría el requisito exigido en el artículo 2.a).iii) de la Directiva 2011/96/UE para que la misma sea aplicable a la entidad en cuestión y pueda evitar el fenómeno de la doble imposición en la percepción de beneficios societarios comunitarios distribuidos por parte de sus entidades filiales.

\subsection{Definición de establecimiento permanente}

Centrándonos en la noción de establecimiento permanente prevista en el artículo 2 de la Directiva 2011/96/UE, esta lo define como un centro actividades fijo situado en un país miembro de la Unión Europea mediante el cual se realice, en todo o en parte, las actividades empresariales de una sociedad sita en otro Estado miembro; y, en la medida en que los beneficios del centro actividades estén sujetos a imposición en el Estado miembro en el que está situado dicho establecimiento permanente, en virtud de un tratado bilateral en materia fiscal o, en su defecto, en virtud de lo que disponga la legislación nacional del país comunitario donde aquél se encuentre establecido.

A priori, aunque el artículo 2.b) de la Directiva 2011/96/UE brinda un concepto parco de establecimiento permanente, la compleja casuística que presenta esta noción (como puede constatarse en el artículo 5 del Modelo de Convenio de la OCDE y sus comentarios ${ }^{51}$ ) parece colmarse, a través de los convenios bilaterales de doble imposición y las legislaciones nacionales de los países comunitarios. Aunque Fabra ${ }^{52}$ entiende idónea la técnica empleada

${ }^{50}$ Por ejemplo, en la Ley 27/2014, de 27 de noviembre, del Impuesto sobre Sociedades español, se prevén distintos tipos de gravamen en función de diferentes modalidades societarias y regímenes fiscales específicos previstos en el artículo 29 , a saber, un tipo de gravamen general del $25 \% ; 15 \%$ para las entidades de nueva creación; $20 \%$ sociedades cooperativas; $10 \%$ a las entidades comprendidas en la Ley 49/2002 antes reseñada; $1 \%$ a las sociedades de inversión de capital, fondos de inversión; sociedades de inversión inmobiliaria, fondos de inversión inmobiliaria y fondo de regulación del mercado hipotecario; $0 \%$ a los fondos de pensiones; $30 \%$ entidades de crédito y las dedicadas a la exploración, investigación y explotación de yacimientos y almacenamientos subterráneos de hidrocarburos y $25 \%$ en determinados casos; $4 \%$ entidades ZEC en Canarias. Otra casuística podríamos encontrarla en los grupos de sociedades holding dedicadas a recibir rentas derivadas de la tenencia y enajenación de participaciones en un grupo societario comunitario que quedarían exentas, conforme al régimen establecido en el impuesto sobre sociedades correspondiente.

${ }^{51}$ OCDE, Model Tax Convention...cit., pp. 31 y siguientes, y 116 y siguientes.

${ }^{52}$ FABRA VALLS, M., «Contraste entre la Directiva sobre matrices... cit., p. 73». 
por la norma comunitaria al evitar, de ese modo, conflictos de calificación, debe hacerse eco de dos cuestiones relevantes intrínsecamente ligadas entre sí que pueden emanar de la parquedad del concepto de establecimiento permanente y la delegación de la cuestión a las jurisdicciones fiscales nacionales y los convenios bilaterales de doble imposición (no siempre homogéneos).

La primera, aunque resulte lógico la predilección de las soberanías fiscales por entender el concepto de establecimiento permanente del modo más amplio posible para extender sus tentáculos a todas aquellas manifestaciones de riqueza que afloren en su jurisdicción, en el presente caso, la calificación o no de establecimiento permanente supondría una pérdida recaudatoria sobre las rentas derivadas de las distribuciones de beneficios. La combinación de esta circunstancia unida a la complejidad del concepto de establecimiento permanente y la confluencia de operaciones triangulares o de mayor proyección en varias jurisdicciones europeas podría dar lugar a conflictos de calificación sobre la existencia o no de un establecimiento permanente, a los efectos de aplicar las medidas contenidas en la Directiva 2011/96/UE para evitar la doble imposición. Entre la amplia casuística contenida en los comentarios del Modelo de Convenio de la OCDE, cabe señalar el ejemplo del comentario $5.19^{53}$ donde se alude que una zona en la que se desarrollan actividades que forman parte de un solo proyecto, y que constituye una unidad comercial coherente, puede carecer de la coherencia geográfica necesaria para considerarla como un lugar de negocios único. Por ejemplo, si un consultor trabaja en diferentes sucursales con emplazamientos separados en el marco de un único proyecto de formación de los empleados de un banco, habrá que considerar cada una de las sucursales como una unidad independiente. No obstante, si el consultor se traslada de una oficina a otra dentro de la misma sucursal, habrá que considerar que permanece en el mismo lugar de negocios. La sucursal ubicada en un mismo lugar posee una coherencia geográfica que no está presente en el caso del consultor que se traslada de una sucursal a otras con diferente emplazamiento. Sin embargo, frente a la proliferación de estos complejos supuestos tridimensionales o incluso de mayor alcance, la norma comunitaria se limita a delegar la resolución del problema a las legislaciones tributarias nacionales y a los convenios "bilaterales" con los riesgos potenciales de inseguridad jurídica que ello le puede deparar al contribuyente.

Y la segunda, la resolución de los problemas de calificación de establecimiento permanente podría generar disfuncionalidades importantes en detrimento del contribuyente en tanto en cuanto las instancias judiciales nacionales de los diferentes países comunitarios afectados por las operaciones de los grupos

\footnotetext{
${ }^{53}$ OCDE, Model Tax Convention... cit., p. 120.
} 
societarios europeos podrían adoptar decisiones jurídicas distintas que tuvieran como consecuencia la no consideración de establecimiento permanente, y con ello, la producción de casos de doble imposición. A su vez, el procedimiento amistoso contemplado en el Modelo de Convenio de la OCDE no ofrece garantías suficientes de poder alcanzar una solución equitativa, dado que las autoridades competentes de los Estados miembros no están obligadas a alcanzar un acuerdo a través de ese mecanismo procedimental.

Aunque siempre quedaría el recurso ante el Tribunal de Justicia de la Unión Europea, la parquedad de un concepto tan importante como el de establecimiento permanente en el artículo 2.b) de la norma comunitaria podría generar disfuncionalidades en su aplicación pudiendo menguar los cimientos esenciales del mercado interior europeo (fundamentalmente, libre circulación de capitales, servicios y libertad de establecimiento) y socavando principios inherentes a un ordenamiento legal como sería el principio de seguridad jurídica, entre otros. Por ello, a nuestro humilde parecer, dicho precepto podría colmarse mediante la remisión al artículo 5 del Modelo de Convenio de la OCDE y sus comentarios como instrumentos jurídicos integradores de los numerosos interrogantes que aquel precepto comunitario puede aflorar a la hora de determinar, si existe o no estableciendo permanente en un país u otro, con la ventaja de que dichas fuentes integradoras alcanzarían una proyección multilateral (y no bilateral y/o disfuncional) con la posibilidad de aplicar los criterios hermenéuticos del ordenamiento jurídico comunitario. Todo lo cual, podría brindar mayor seguridad jurídica al contribuyente europeo evitando distorsiones y discriminaciones en el funcionamiento del mercado interno europeo.

\section{REQUISITOS MATERIALES DE APLICACIÓN DE LA DIREC- TIVA 2011/96/UE Y LA DOBLE IMPOSICIÓN}

El cumplimiento de los condicionantes establecidos en el ámbito objetivo y subjetivo de la Directiva 2011/96/UE no resulta suficiente para la aplicación de dicha norma. A todo lo estudiado en los epígrafes precedentes, cabe añadir la exigencia del cumplimiento de unos requisitos materiales que permitan la aplicación y eficacia de la Directiva 2011/96/UE que, en parte, amplía el ámbito subjetivo de dicha norma al definir lo que debe entenderse por sociedad matriz y filial. Algunas de las cuestiones que se van a analizar en este apartado, por ejemplo, la exigencia de una participación mínima en otra entidad y de un período de permanencia mínimo en la titularidad de dicha participación no es más que una manifestación, por un lado, de la voluntad de los Estados miembros de evolucionar de manera paulatina en la ardua y compleja tarea 
de la armonización fiscal en la tributación de las rentas societarias en el contexto del mercado interior europeo; y por otro, en íntima conexión con el primero, del recelo de las distintas soberanías fiscales europeas en la cesión de poder tributario.

\subsection{Porcentaje mínimo de titularidad en el capital social}

El primer requisito exigido en el artículo 3 de la Directiva 2011/96/UE comprende que las sociedades que cumplan las condiciones previstas en el artículo 2 (referido al ámbito subjetivo de la norma) posean, al menos, una participación del $10 \%$ en el capital de otra sociedad (filial) situada en otro Estado miembro de la Unión Europea. En este caso, la norma exige una participación mínima del $10 \%$ por parte de la sociedad matriz en la entidad filial para que la Directiva 2011/96/UE sea aplicable a la distribución de beneficios obtenidos por la primera. Con lo cual, las sociedades matrices que participan menos de un 10\% en alguna de sus sociedades filiales domiciliadas en otro Estado miembro de la Unión Europea quedarían excluidas del ámbito de aplicación de la norma fiscal europea y, por consiguiente, las distribuciones de beneficios percibidas de sus filiales, en principio, soportarán la retención en la fuente y la doble imposición sobre dichos beneficios obtenidos ${ }^{54}$.

Un argumento en defensa de esta restricción de participación mínima del $10 \%$, sería que la misma constituye una evolución en favor del contribuyente, respecto a la exigencia material inicialmente requerida por la Directiva 90/435/CE (ex. artículo 3.1.a)) del 25\% que se ha ido reduciendo hasta el $20 \%, 15 \%$ y $10 \%$, respectivamente, desde la entrada en vigor de la Directiva 2003/123/CE. Lo cual, podría inducirnos a pensar que, en un futuro, dicha participación pueda reducirse en aras de que esta regulación jurídica se adapte a las complejidades jurídicas, económicas y financieras de los grupos empresariales en la esfera económica internacional europea y mundial. En consonancia con este postulado, Meier y Goergen ${ }^{55}$ entienden que la exigencia de este requisito comprende una opción de política legislativa que no impedirá a los Estados miembros exigir porcentajes inferiores al 10\% para poder aplicarse los beneficios de la norma comunitaria, como sucede, por ejemplo, en el impuesto sobre sociedades español ${ }^{56}$. A nuestro modesto parecer, en la medida que cierta mayoría de

54 Todo esto, sin perjuicio de lo que, en su caso, establezcan las medidas unilaterales previstas en las legislaciones domésticas y en los convenios de doble imposición suscritos por los países comunitarios para el tratamiento de dichas fuentes rentas a los contribuyentes que no les resultara de aplicación la Directiva 2011/96/UE.

${ }^{55}$ Citados en LETE ACHIRICA, C., «Régimen fiscal de las distribuciones...cit., p. 439».

${ }^{56}$ El artículo 21.1.a) de la Ley 27/2014, de 27 de noviembre, del Impuesto sobre Sociedades rubricado "Exención para evitar la doble imposición sobre dividendos y rentas derivadas de 
países comunitarios adopten disposiciones similares, es decir la reducción del porcentaje de participación por debajo del 10\%, sería recomendable, a medio o corto plazo, la modificación de la Directiva 2011/96/UE, en el sentido de reducir dicho porcentaje de participación, en aras de evitar distorsiones en la localización de empresas en el mercado interior europeo motivado por este tipo de disfuncionalidad regulatoria.

Por otra parte, el artículo 3.1.a).i) de la Directiva 2011/96/UE no aclara si la participación que la sociedad matriz debe tener en la entidad filial debe ser directa o si también dicha participación del $10 \%$ puede ser indirecta. A nuestro modesto entender, la generalidad del precepto en concordancia con los objetivos y fundamentos de la norma ya expuestos permiten concluir que puede entenderse cumplido el requisito de la participación mínima indirecta del 10\%. Sin embargo, Calderón y Martín ${ }^{57}$ señalaron que, según parece, la Comisión entendió, de una forma posiblemente cuestionable, que el porcentaje debía ser directo en tanto en cuanto la reducción del porcentaje de participación ampliaba suficientemente la Directiva, sin necesidad de incluir la referencia a participaciones indirectas. No obstante, entendemos que dicha cuestión deberá ser disipada por la jurisprudencia comunitaria en tanto en cuanto es habitual la participación indirecta en filiales de segundo y ulterior nivel alcanzando el umbral mínimo exigido por la Directiva 2011/96/UE para aplicar las medidas para evitar la doble imposición contenidas en la misma ${ }^{58}$. Asimismo, la participación exige la condición de titular dominical de las participaciones ${ }^{59}$, sin que quepa extender tal condición a los usufructuarios o tomadores en prenda de los títulos, ni los copropietarios de acciones invisibles ${ }^{60}$.

la transmisión de valores representativos de los fondos propios de entidades residentes y no residentes en territorio español" prevé unos porcentajes de participación mínimos del 5\%.

${ }^{57}$ CALDERÓN CARRERO, J. M., y MARTÍN JIMÉNEZ, A., «La Directiva relativa al sistema común...cit., pp. 1083-1084».

${ }^{58}$ Piénsese en el ejemplo de la sociedad matriz M, residente en España, que participa al $20 \%$ la sociedad filial F, residente en Francia. A la vez, esta última participa al $20 \%$ otra entidad filial C, también residente en Francia. En este caso, la participación de la sociedad matriz $\mathrm{M}$ tiene sobre la entidad filial $\mathrm{C}$ cumplía el requisito mínimo del $10 \%$, con lo cual la primera podrá aplicarse las medidas contenidas en el artículo 4.1 de la Directiva 2011/96/UE para evitar la doble imposición internacional económica colectiva que se generaría de entidades filiales de ulterior nivel a la sociedad C. Por el contrario, si la sociedad matriz M participara al $10 \%$ la sociedad filial $\mathrm{F}$ que, a su vez, participara al $10 \%$ la entidad filial C, no se cumpliría el requisito de participación indirecta mínima del $10 \%$, con lo cual la sociedad matriz M soportaría la doble imposición internacional sobre la parte proporcional de los beneficios distribuidos de forma indirecta por la sociedad filial C, sin poder aplicarse las medidas para evitar dicho fenómeno contenidas en la Directiva 2011/96/UE.

${ }^{59} \mathrm{O}$, en su caso, la posesión de los derechos de votos que aquellos países europeos adopten mediante acuerdos comunitarios, por mor del artículo 3.2.a) de la Directiva 2011/96/UE

${ }^{60}$ En la misma línea, LETE ACHIRICA, C., $<<$ Régimen fiscal de las distribuciones...cit., pp. 439-441. RIBES, RIBES, A. (2005), cit., p. 107 donde, a su vez, se citan con el mismo 
En lo que respecta al segundo supuesto contenido en el artículo 3 de la Directiva 2011/96/UE que define el estatus jurídico de sociedad matriz, a los efectos de aplicación de dicha norma, se refiere a una sociedad, en las mismas condiciones que el caso anterior, que posea una participación mínima del $10 \%$ en otra empresa situada en el mismo Estado miembro que la primera, pero que esté controlada total o parcialmente por un establecimiento permanente de la sociedad matriz situado en otro Estado miembro. Se trataría de un supuesto que denota laxitud por parte de la Directiva 2011/96/UE en la previsión de las gestiones de planificación y operatividad de los grupos de sociedades internacionales dentro del mercado interior europeo en armonía con los fundamentos y objetivos esenciales de dicha norma.

Finalmente, cabe apuntar que ni el precepto estudiado ni el resto del cuerpo normativo de la Directiva 2011/96/UE aclaran el significado de "control total o parcial" por parte del establecimiento permanente, lo cual permitiría comprender tanto el significado de "titularidad" como el de "control en el órgano de administración o derechos de voto",62. Si bien, esta segunda hipótesis no parece tener encaje en tanto en cuanto el apartado dos del precepto contempla, de manera independiente al apartado primero, la posibilidad de que los Estados miembros pueden sustituir el criterio de la participación del capital por el de la posesión de los derechos de voto que veremos a continuación. De lo cual, se colige una delimitación conceptual del término "control total o parcial" y el de la "posesión de los derechos de voto", contemplando este último como

parecer a Hosson y Vanistendael, Martín y Calderón. Sentencia del Tribunal de Justicia de la Unión Europea État belge-Service public federal Finances/Les Bergers du Vieux Tauves SA, de fecha 22 de diciembre de 2008, que se decanta igualmente por la tesis de denegar los beneficios de la norma comunitaria a los usufructuarios de los títulos.

No obstante, los Estados miembros, en el ámbito de sus competencias fiscales soberanas, podrían ampliar el ámbito subjetivo y flexibilizar la exigencia de los requisitos materiales, en tal sentido, siempre que no constituyan medidas de competencia fiscal perniciosa ni se generen distorsiones en el funcionamiento del mercado interior.

${ }^{61}$ Nótese el ejemplo de una sociedad matriz M, residente en España, que participa en un $10 \%$ a una sociedad filial $\mathrm{F}$, también residente en España. A su vez, el establecimiento permanente EP, residente en Francia, controla totalmente al $80 \%$ la sociedad filial F. En consonancia con esta primera hipótesis, la Directiva 2011/96/UE sería aplicable a los beneficios distribuidos por la sociedad filial $\mathrm{F}$ al establecimiento permanente $\mathrm{EP}$, y la posterior repatriación de beneficios del EP a la sociedad matriz M.

62 Piénsese el ejemplo de una sociedad matriz M, residente en España, que participa en un $10 \%$ a una sociedad filial $\mathrm{F}$, también residente en España. A su vez, el establecimiento permanente EP, residente en Francia, controla totalmente la sociedad filial F mediante la titularidad de los derechos de voto. En este caso, si éste fuera el sentido del precepto, la Directiva 2011/96/UE sería aplicable a los beneficios distribuidos por la sociedad filial $\mathrm{F}$ al establecimiento permanente EP, y la posterior repatriación de beneficios del EP a la sociedad matriz M. 
una facultad otorgada a los países miembros independiente de los supuestos establecidos en el artículo 3.1 de la Directiva 2011/96/UE.

\subsection{Requisitos potestativos de los Estados miembros}

El apartado 2 del artículo 3 de la Directiva 2011/96/UE complementa los requisitos materiales exigibles para la aplicación de dicha norma mediante el otorgamiento a los Estados miembros de dos facultades no concurrentes cuya aplicación puede dar lugar a que se produzca el fenómeno de la doble imposición en el mercado interior europeo por inaplicación de la Directiva 2011/96/UE.

La primera facultad que concede el precepto reseñado comprende la posibilidad de que el Estado miembro sustituya el criterio de la participación en el capital social de la entidad filial por el de posesión de derechos de voto. Si un Estado miembro optara por aplicar este último criterio, en principio, será suficiente con que el contribuyente acredite el título que le otorga los derechos de voto para poder aplicarse las medidas contenidas en la Directiva 2011/96/UE para evitar la doble imposición internacional jurídica y la doble imposición económica. La sustitución de este criterio por el de participación en el capital social podría abrir el elenco de contribuyentes que podrían beneficiarse de las medidas contenidas en la norma comunitaria para evitar la doble imposición.

La segunda facultad que el artículo 3.2 de la Directiva 2011/96/UE concede a los Estados miembros de la Unión Europea es la no aplicación de la norma, si la participación en el capital exigido en el apartado primero de este precepto no se conserva por un período mínimo ininterrumpido de dos años. Luego, no bastaría con que las sociedades cumplan los requisitos establecidos en el artículo 2 de la Directiva 2011/96/UE, ni tengan la participación mínima exigida en este artículo 3, ni tampoco que se trate de un supuesto comprendido en el ámbito objetivo de la norma es decir la distribución de beneficios entre sociedades matrices y filiales o establecimientos permanentes. Además, la participación exigida del $10 \%$ debe tener un período mínimo de conservación de dos años. Sin el cumplimiento de este requisito, la distribución de beneficios soportaría los nocivos efectos de la doble imposición, sin perjuicio de lo establecido en los convenios de doble imposición y las medidas unilaterales establecidas en la legislación doméstica de los Estados miembros.

Sin embargo, la exigencia de este requisito material por parte de los países comunitarios que optaran por aplicarlo plantea, al menos, una cuestión de importante trascendencia para su aplicación, a saber, si el período mínimo de dos años debe ser cumplido previamente a la aplicación de la Directiva 2011/96/UE; 
o, si por el contrario, la adquisición de la participación mínima en el capital social de otra entidad es suficiente para la aplicación inmediata de las medidas contenidas en aquella para evitar el fenómeno de la doble imposición requiriéndose, en tal caso, un período mínimo de permanencia de dos años, desde aquel momento. En este último supuesto, la sociedad propietaria de la participación mínima del 10\% podría aplicarse la Directiva 2011/96/UE en todo momento, a condición de que llegue a alcanzar el período mínimo de permanencia de dos años exigido.

La respuesta a esta cuestión debe ser afirmativa, tal y como lo ha entendido la Corte comunitaria, en la Sentencia del Tribunal de Justicia de las Comunidad Europea, asuntos C-283/94 Denkavit Internationaal BV, asunto C-291/94, VITIC Amsterdam BV, asunto C-292/94, Voormeer BV, de fecha 17 de octubre de 1996. En dicha resolución, el tribunal esgrimió que los Estados miembros no pueden supeditar la concesión de los beneficios previstos en el artículo 5 al requisito de que la sociedad matriz haya poseído, previamente, una participación en la filial durante el período mínimo fijado en virtud del apartado 2 del artículo 3, siendo suficiente, en estos casos, que la sociedad matriz se comprometa unilateralmente a respetar el plazo mínimo de participación ${ }^{63}$.

\section{MEDIDAS PARA EVITAR LA DOBLE IMPOSICIÓN SOBRE LA DISTRIBUCIÓN DE BENEFICIOS EN LA DIRECTIVA 2011/96/UE}

Los artículos 4 a 6 de la norma comunitaria establecen las medidas para evitar la doble imposición en sus dos modalidades, jurídica y económica. Dadas las particularidades de cada una y las medidas adoptadas para evitar la doble imposición, estas serán analizadas por separado siguiendo la casuística prevista en el ámbito objetivo de la norma target.

\subsection{Medidas para evitar la doble imposición internacional económica}

El artículo 4 de la Directiva 2011/96/UE se centra exclusivamente en los supuestos de hecho que producen la doble imposición en la distribución de beneficios de los grupos de sociedades internacionales en el mercado interior europeo y las medidas previstas para evitar la doble imposición internacional económica.

El primer apartado del artículo 4 de la Directiva establece el supuesto marco en el que una sociedad matriz o un establecimiento permanente ${ }^{64} \mathrm{de}$

\footnotetext{
${ }^{63}$ Fundamentos jurídicos 32 y 33.

${ }^{64}$ Los establecimientos permanentes pueden aplicarse los mismos métodos para evitar la doble imposición que las empresas nacionales, como ya lo había esgrimido la Sentencia del
} 
esta reciben beneficios distribuidos de una sociedad filial, distintos de los derivados de la liquidación de esta. Haciendo abstracción de este precepto, de los convenios de doble imposición y de las normas de Derecho tributario internacional, nos encontraríamos ante un supuesto de doble imposición internacional económica, dado que los beneficios obtenidos por la sociedad filial serán gravados, en su país de residencia, mediante la obligación personal de contribuir al deber de sostenimiento de los gastos público por su renta mundial; $\mathrm{y}$, correlativamente, esos mismos beneficios distribuidos a la sociedad matriz o establecimiento permanente sito en un país miembro comunitario distinto serán sometidos nuevamente a gravamen en el impuesto sobre sociedades por la misma obligación personal de contribuir por su renta mundial; o, en el caso de los establecimientos permanentes no residentes, en virtud del principio de territorialidad que someten a gravamen las rentas percibidas en el territorio del Estado miembro donde se encuentran localizados. Con lo cual, se produciría la doble imposición internacional económica al ser sometida a exacción las mismas rentas sobre dos contribuyentes distintos situados en jurisdicciones fiscales diferentes y en el mismo período de tiempo.

\subsubsection{El método de exención íntegra}

La primera medida establecida en el artículo 4.1.a) de la Directiva 2011/96/UE para evitar la doble imposición internacional económica es la aplicación del método de la exención íntegra de las rentas derivadas de la distribución de beneficios realizada por la sociedad filial a la sociedad matriz o al establecimiento permanente. Así, el precepto dispone que el Estado miembro de la sociedad matriz y el del establecimiento permanente "se abstendrán de grabar dichos beneficios". De este modo, las rentas solamente serán gravadas en el Estado miembro donde se encuentra domiciliada la sociedad filial, en virtud de su obligación personal de someter a gravamen las rentas mundiales percibidas por dicha entidad, quedando dichos beneficios exentos de tributación en el país de residencia de la sociedad matriz y, en su caso, del establecimiento permanente.

Tribunal de Justicia de la Comunidad Europea, Saint Gobain, y la Sentencia del Tribunal de Justicia de las Comunidades Europeas, República de Finlandia\&Reino de los Países Bajos C469/98, de fecha 5 de noviembre de 2002, apartado 123: "El Tribunal de Justicia ha declarado que el principio del trato nacional obliga al Estado miembro que sea parte de un convenio internacional bilateral celebrado con un país tercero para evitar la doble imposición a conceder a los establecimientos permanentes de sociedades domiciliadas en otro Estado miembro las ventajas previstas por dicho convenio en las mismas condiciones aplicables a las sociedades domiciliadas en el Estado miembro parte del convenio (véanse las sentencias Saint-Gobain ZN, antes citada, apartado 59, y de 15 de enero de 2002, Gottardo, C-55/00, Rec. p. I-413, apartado 32)”. 
La aplicación del método de la exención íntegra a los beneficios obtenidos por la sociedad matriz de su entidad filial favorece el principio de equidad intracomunitaria ${ }^{65}$ entre las soberanías fiscales imbricadas, dado que las rentas solamente se someten a imposición en el país origen donde se generan, es decir en la jurisdicción de la sociedad filial cuyos beneficios allí generados son sometidos a exacción, sin que el país de destino donde se encuentra localizada la sociedad matriz que recibe los beneficios pueda gravarlos nuevamente; y favorecería la neutralidad fiscal en la importación de capitales que beneficiaría al país destinatario de la inversión ${ }^{66}$. Desde el prisma de los principios constitucionales de justicia tributaria español, el método de la exención casaría con el principio de capacidad económica del contribuyente al no gravarse una manifestación de riqueza virtual en tanto en cuanto ya ha sido sometida a exacción, así como con el principio de no confiscatoriedad.

El método de la exención prevista en la Directiva 2011/96/UE podría presentarse como una opción idónea para evitar el fenómeno de la doble imposición ${ }^{67}$ internacional económica sobre la distribución de beneficios, dado que su aplicación evidencia que dicho fenómeno no se produciría, en lo que respecta a esta categoría o fuente de renta en concreto y dentro del ámbito subjetivo de la norma comunitaria ${ }^{68}$. Al mismo tiempo, responde a los fundamentos (facilitar la creación de grupos societarios en el mercado interior europeo soslayando desventajas, restricciones, distorsiones, etc. derivada de las distintas disposiciones fiscales emanadas por cada uno de los Estados miembros, logrando normas fiscales neutras que no distorsionen la competencia) y objetivos esenciales

\footnotetext{
${ }^{65}$ RUDING, «Informe del Comité Ruding...cit., pp. 223-224».

${ }^{66}$ CALDERÓN CARRERO, J. M., y MARTÍN JIMÉNEZ, A., «La Directiva relativa al sistema común... cit., p. 1.095».

Aunque no debemos obviar la posible discriminación en el tratamiento jurídico tributario de las rentas que soportan las sociedades nacionales que perciben todas sus rentas dentro de la misma jurisdicción frente a las entidades que perciben parte de sus rentas en el ámbito interno y otras proceden de sus inversiones en el exterior, el Tribunal de Justicia de la Unión Europea ha postulado que un Estado miembro no tiene por qué aplicar una norma comunitaria a una situación similar en Derecho interno, sin que ello contravenga el principio de no discriminación (Sentencia del Tribunal de Justicia de las Comunidades Europeas, asunto C- 29/95 Leur-Blöem, de fecha 17-7-1997).

${ }^{67}$ FABRA VALLS, M., «Contraste entre la Directiva sobre matrices...cit., pp. 81 у siguientes». El debate sobre la aplicación de los métodos de exención e imputación divide a la doctrina científica y la comunidad internacional, razón por la cual la adopción de ambos métodos habría impedido el acuerdo necesario para la adopción de la Directiva 2011/96/UE.

El método de la imputación es seguido por Reino Unido, Estados Unidos y otros países, mientras que el método de la exención es adoptados por los países centroeuropeos como Holanda, Francia, Alemania, Bélgica, Suiza y Luxemburgo

${ }^{68}$ Del mismo parecer, Bolkestein, y Magraner citados en PRÓSPER ALMAGRO, A. B., «El nuevo escenario jurídico de la tributación cit., 223 y siguientes». CALDERÓN CARRERO, J. M., y MARTÍN JIMÉNEZ, A., «La Directiva relativa al sistema común... cit., p. 1095».
} 
(favorecer la cooperación, ampliación e integración de los grupos societarios europeos mediante la eliminación de la doble imposición internacional económica).

\subsubsection{El método de imputación}

El artículo 4.1.b) de la Directiva 2011/96/UE comprende los mismos supuestos de hecho analizados en los párrafos precedentes, pero prevé la aplicación del método de la imputación ordinaria para eliminar la doble imposición. La aplicación de este método se traduciría en que los beneficios percibidos por la sociedad matriz de su entidad filial situada en otro Estado miembro serán gravados en el impuesto sobre sociedades de la primera pudiendo deducirse la fracción del impuesto soportado por la entidad filial con el límite máximo del impuesto resultante que le hubiera dado a pagar a la sociedad matriz ${ }^{69}$, aunque ésta no integre en la base imponible otros beneficios ${ }^{70}$. Piénsese en el ejemplo de una sociedad matriz M, residente en España, que recibe unos dividendos de la sociedad filial F, residente en Italia. El importe de dividendos asciende a $100.000 €$ habiendo soportado un impuesto $30.000 €$, en Italia. Si la sociedad española tuviera una cuota líquida en el impuesto de sociedades por importe de $28.000 €$, sólo podrá deducirse $28.000 €$ del impuesto de sociedades italiano que soportó la sociedad filial F, perdiendo la diferencia $(2000 €)$ del exceso de gravamen, como consecuencia del límite previsto en el método de la imputación ordinaria regulado en la norma comunitaria.

Del mismo modo, el método de la imputación ordinaria podrá aplicarse a los beneficios obtenidos por los establecimientos permanentes situados en un país miembro de la Unión Europea de una sociedad matriz localizada en otro Estado miembro de aquella que perciben beneficios de sociedades filiales domiciliadas en el mismo país europeo que la sociedad matriz o en cualquier otra jurisdicción comunitaria. Asimismo, la aplicación del método de imputación establecida en este precepto es extensible a los beneficios que han sido sometidos a gravamen por el impuesto de sociedades de la entidad filial y de toda filial de ulterior nivel, todas ellas domiciliadas en los Estados miembros de la Unión Europea.

${ }^{69}$ CALDERÓN CARRERO, J. M., y MARTÍN JIMÉNEZ, A., «La Directiva relativa al sistema común... cit., p. 1103». La sentencia del Tribunal de Justicia de la Unión Europea, asunto Test Claimants C-446/04, citada en esta obra determinó la no obligatoriedad de deducir la totalidad del impuesto pagado en el extranjero.

${ }^{70}$ Sentencia del Tribunal de Justicia de las Comunidades Europeas, asunto Cobelfret NV y Belgische Staat, C-138/07, de fecha 12-2-2009. En este sentido se pronunció en un asunto en el que el Gobierno belga pretendía limitar la aplicación de la deducción del impuesto soportado por la sociedad matriz. 
El método de la imputación ordinaria contemplado en este precepto favorece el principio de equidad personal en tanto en cuanto las rentas percibidas con ocasión de la distribución de beneficios societarios tendrán el mismo trato jurídico-fiscal con independencia de su origen nacional o comunitario, en el sentido de que ambas rentas serán integradas en la base imponible de las sociedades contribuyentes, con independencia de las medidas aplicadas en la estructura del impuesto para evitar la doble imposición internacional; respecto de aquellas percibidas dentro de la misma jurisdicción comunitaria, amén de los supuestos en que el tipo de gravamen en la fuente es superior al del país de residencia. Desde el punto de vista de la equidad internacional, el método de la imputación ordinaria contribuye a un reparto de las bases imponibles entre los países implicados en la exacción de las rentas transfronterizas en tanto en cuanto ambos someten aquellas a gravamen siendo el país destino de los beneficios distribuidos el encargado de aplicar los métodos para evitar la doble imposición internacional sobre aquellos.

La neutralidad en la exportación de capitales se ve favorecida con la aplicación del método de la imputación ordinaria en tanto en cuanto el país exportador puede someter a gravamen las rentas procedentes del país origen donde aquellas se han generado repercutiendo negativamente en las inversiones económicas comunitarias al poder anular, en determinados casos, los incentivos a la atracción de capital establecidos en el país destino de la inversión, dado que el límite de deducción del impuesto extranjero al devengado en la cuota del impuesto no evitaría la doble imposición, produciéndose una discriminación en las condiciones de competencia entre las empresas nacionales y extranjeras ${ }^{71}$. Si bien, Calderón y Martín ${ }^{72}$ señalan dos aspectos relevantes referidos a la aplicación del método de la imputación ordinaria contenida en la Directiva 2011/96/UE. Por un lado, no se determina la forma en que debe computarse el límite del método de la imputación, es decir per item/per basket/per country/ overall. Los autores apuntan que tal opción no resulta neutral, dado que, dependiendo de la modalidad por la que se opte, el cross-crediting o compensación entre impuestos extranjeros pagados a tipos de gravamen diferentes resultará más o menos amplio, maximizándose o minimizándose con ello las posibilidades de deducción. Por añadidura, cabe apuntar que la norma comunitaria tampoco prevé la posibilidad de que la deducción del impuesto extranjero resulte

71 Falcón, citado en GONZÁLEZ ORTIZ, D., «La Directiva 90/435/CEE desde la perspectiva de los principios constitucionales de justicia tributaria», en Noticias de la Unión Europea (Valencia), 244 (2005) 91 y siguientes. SÁNCHEZ JIMÉNEZ, Mª A., La doble imposición ... cit., p. 206. CALDERÓN CARRERO, J. M., y MARTÍN JIMÉNEZ, A., «La Directiva relativa al sistema común... cit., p. 1095-1097».

72 CALDERÓN CARRERO, J. M., y MARTÍN JIMÉNEZ, A., «La Directiva relativa al sistema común... cit., pp. 1103-1104». 
posible en el periodo impositivo en que deba aplicarse el método de la imputación; $\mathrm{y}$, en consecuencia, pueda practicarse dicha deducción en periodos sucesivos (carry forward of unused credits $)^{73}$.

En el contexto de los principios jurídicos de justicia tributaria españoles, en determinados casos, la aplicación del método imputación ordinaria en los supuestos de doble imposición internacional económica podría transgredir el principio de capacidad económica al someter a gravamen rentas ficticias y quebrantar el principio de no confiscatoriedad ${ }^{74}$.

A nuestro modesto entender, la aplicación del método de la imputación ordinaria en los términos en que viene configurada en la Directiva 2011/96/UE no se presenta como una técnica idónea para evitar la doble imposición internacional económica por las razones ya expuestas en los párrafos precedentes, lo cual no coadyuvaría al logro del objetivo esencial de la Directiva fiscal europea consistente en la creación, ampliación y consolidación de los grupos societarios mediante la eliminación de esta modalidad de doble imposición ${ }^{75}$. No obstante, habrá que estar a la transposición que hayan realizado los países comunitarios de dicha norma en cuyo caso aún podrían persistir ciertas diferencias que den lugar a distorsiones en la localización de empresas en el mercado interior europeo, atendiendo a aquellas jurisdicciones que consiguen evitar el fenómeno de la doble imposición internacional económica, en función de los métodos y la configuración de los mismos traspuestas en sus respectivas legislaciones tributarias nacionales. Y, en íntima conexión con esta apreciación, el método de la imputación ordinaria podría no casar con los fundamentos de la Directiva 2011/96/UE, en el sentido de que pueden subsistir ligeras distorsiones y

\footnotetext{
${ }^{73}$ Aunque entendemos que esta cuestión pueda dejarse dentro del margen de actuación de los Estados miembros, si entendemos la necesidad de que la Directiva 2011/96/UE precisara los mecanismos de aplicación del método de la imputación ordinaria en aras de evitar socavar la neutralidad pretendida por la norma mediante la aplicación de aquellos procedimientos más perniciosos para el contribuyente que no elimine por completo el fenómeno de la doble imposición.

${ }^{74}$ A título ejemplificativo, pueden citarse aquellos supuestos en que los tipos impositivos en el país de la sociedad matriz son mayores que los del Estado de la fuente, ponderando cada caso concreto; o, en las exacciones en cascada por dividendos procedentes de diferentes países con restricciones en la aplicación del método de la imputación ordinaria en el país de residencia de la empresa matriz.

${ }^{75}$ COMISIÓN, «Hacia un mercado interior sin obstáculos fiscales. Una estrategia destinada a dotar a las empresas de una base imponible consolidada del impuesto sobre sociedades para sus actividades a escala comunitaria», en COM (Bruselas) (2001) 582 final, p. 46. El comité expertos del informe "Hacia un mercado interior sin obstáculos fiscales" cuestionaba el método de imputación al entender que incentivaban la inversión interna, a la vez, que desalentaban las inversiones comunitarias transfronterizas atendiendo a la jurisprudencia de la Corte comunitaria, asuntos Safir, Verkooijen y Saint-Gobain.
} 
obstáculos que generen discriminaciones, falta de neutralidad en la localización de factores productivos, y merma de las libertades de circulación en el mercado interior europe ${ }^{76}$. A todo esto, Ribes ${ }^{77}$ apunta la mayor dificultad que entraña este método al exigir conocer cuál ha sido el impuesto pagado por la filial, respecto a los beneficios con cargo a los cuales se abonan los dividendos. Quizás, hubiera sido preferible que la norma comunitaria se hubiera decantado por el método de la imputación íntegra ${ }^{78}$, pero, coincidiendo con Sánchez ${ }^{79}$, pocos Estados miembros adoptarían el método de la imputación íntegra en tanto en cuanto no beneficia a la Hacienda estatal, cuando el impuesto extranjero supera el que hubiera correspondido pagar en su propia jurisdicción, aun cuando dicho método logra eliminar la doble imposición. Por ello, los Estados abogan se decantan por el método de la imputación ordinaria.

5.1.3. Medidas para evitar la doble imposición en el régimen de sociedades transparentes

El artículo 4.2 de la Directiva 2011/96/UE también prevé la aplicación de los métodos de exención íntegra y el de la imputación total para aquellos supuestos en que la sociedad matriz de un Estado miembro recibe beneficios de otra entidad filial domiciliada en otro país comunitario calificada por el Estado miembro de la sociedad matriz como transparente. Esta cuestión plantea problemas por el reconocimiento o no de la personalidad jurídica al ente independiente de la de sus $\operatorname{socios}^{80}$ y de identidad del objeto de gravamen sobre el que se puede aplicar la deducción por doble imposición.

En el presente caso, sucede que la entidad filial puede no ser considerada como transparente por el Estado miembro donde se ha creado sino que la Directiva 2011/96/UE atribuye al país comunitario de la sociedad

${ }^{76}$ VOGEL, K., «Which method should the European Community adopt for the avoidance of double taxation?», in Bulletin-Tax Treatry Monitor (Ámsterdam), 56, 1 (2002) 4 y siguientes.

${ }^{77}$ RIBES, RIBES, A. ,(2005), cit., p. 103.

78 ARIAS ABELLÁN, M. D., «Impuesto sobre Sociedades; la deducción por doble imposición de dividendos e internacional en las entidades financieras», en Revista Española de Derecho Financiero (Madrid), 53 (1987) pp. 31 y siguientes. La autora abogaba por el método de la imputación íntegra como una de las alternativas para evitar la doble imposición. Aunque el objeto del trabajo versaba sobre la doble imposición de dividendos e internacional por las entidades financieras, parece referirse a dicha técnica con carácter general para todas las rentas.

${ }^{79}$ SANCHEZ JIMENEZ, Ma . A., La doble imposición... cit., pp. 29 y siguientes, y pp. 204 y siguientes.

${ }^{80}$ RUBIO GUERRERO, J. J., «Los principios básicos... cit., p. 46». PALAO TABOADA, C., «La aplicación de los convenios de doble imposición a las sociedades personalistas: el informe de la OCDE de 1999»», en Revista de Contabilidad y Tributación (Madrid), 209-210, 49 (2000) 62. 
matriz competencias para calificar a aquélla corporación como transparente, a los efectos de aplicar, en su caso, las medidas para evitar la doble imposición comprendidas en la norma, sin la determinación de ningún criterio jurídico, objetivo u orientativo en la Directiva fiscal europea. Las consecuencias derivadas de esa atribución de calificación de la sociedad filial como transparente podría dar lugar a que la sociedad matriz no pudiera aplicarse ni el método de la exención integral ni el de la imputación ordinaria en tanto en cuanto el país de la sociedad matriz podría entender que lo que se produce no es una distribución de beneficios en sentido propio.

En el caso de una entidad filial, sujeto pasivo del impuesto sobre sociedades, la totalidad de sus beneficios son sometidos a imposición, y la traslación dominical de aquellos a sus socios o accionistas se produciría mediante una distribución de beneficios societarios, previamente acordado en una junta general. Por el contrario, en el caso de las sociedades transparentes, se produce una imputación directa de los beneficios de la empresa a los socios, sin que aquella entidad transparente tribute por el impuesto sobre sociedades. En este espectro, no cabría pues que el Estado miembro de la sociedad matriz concediera la aplicación del método de la exención integral o el de la imputación ordinaria a aquélla al considerar que la entidad filial domiciliada en otro Estado miembro es transparente; $\mathrm{y}$, en consecuencia, no se reconocería el derecho a deducir ninguna fracción de impuesto en el otro país mediante la aplicación del método de la imputación total o derecho a exonerar de gravamen los beneficios imputados y procedentes de la sociedad filial. Frente a esta eventual problemática que podría suscitarse en aplicación de la Directiva 2011/96/UE, la norma permite al país miembro de la sociedad matriz calificar a la entidad filial como transparente, pero sin alterar el régimen jurídico-tributario previsto en la normativa fiscal europea. Con lo cual, la mera consideración de la sociedad filial como transparente por parte de las autoridades fiscales de la sociedad matriz no constituye un óbice a la aplicación de los métodos de exención e imputación previstos en la Directiva 2011/96/UE. Para reforzar este posicionamiento, la norma puntualiza que la exención o el gravamen de los beneficios que generase el derecho a la aplicación del método de la imputación ordinaria requiere que aquellos beneficios los haya recibido la sociedad matriz de manera real y efectiva. Esta matización se pone de manifiesto en la norma cuando añade la expresión "en el momento en que éstos se perciben" tanto en el párrafo primero como en el segundo del apartado 2 del artículo 4 de la Directiva 2011/96/UE.

No cabe duda alguna de que la previsión normativa antedicha no solamente evita supuestos de doble imposición internacional económica sobre la distribución de beneficios por disparidades hermenéuticas o posibles arbitrariedades realizadas por los países miembros comunitarios sino que también contribuye a evitar la 
proliferación de litigios nacionales y comunitarios por este tipo de divergencias. $\mathrm{Y}$, a su vez, permite al legislador comunitario evitar realizar un pronunciamiento concreto sobre la compatibilidad de algunos regímenes de transparencia fiscal con el Derecho comunitario, preservando determinados mecanismos de rentas o transparencia fiscal por parte de los países comunitarios ${ }^{81}$.

Los artículos 4.4 y 4.5 de la Directiva 2011/96/UE adelantan la aprobación de un sistema común del impuesto sobre sociedades en el futuro, sin mayor concreción, condicionando la vigencia de los apartados 1 y 2 de dicho precepto hasta la aprobación de aquel. Los avances paulatinos y escalonados logrados hasta la fecha en el ámbito del mercado interior europeo en la lucha contra el fenómeno de la doble imposición internacional nos podrían permitir ser optimistas en cuanto a esta propuesta de sistema común del impuesto sobre sociedades en el que, quizás podría llegar a tener cabida el método de la imputación ordinaria como técnica para evitar la doble imposición internacional en la distribución sobre beneficios y adecuarse a los fundamentos y objetivos esenciales propugnados por la Directiva 2011/96/UE.

Finalmente, el artículo 4.3 de la Directiva 2011/96/UE faculta los Estados miembros la posibilidad de prever que los gastos de participación y las minusvalías derivadas de la distribución de beneficios de la sociedad filial no sean deducibles del beneficio imponible de la sociedad matriz. En tal caso, los gastos de gestión derivadas de la participación social a tanto alzado no podrían exceder de un 5\% de los beneficios distribuidos por la sociedad filial. A priori, más allá de estas consideraciones, la regulación contenida en este precepto no tendría incidencia en el fenómeno de la doble imposición internacional, amén de posibles sobrecostes fiscales que produjeran gastos excesivos sobrevenidos o minusvalías cuantitativas importantes derivadas de cualquier eventualidad.

\subsection{Medidas para evitar la doble imposición jurídica}

El artículo 5 de la Directiva 2011/96/UE dispone la eliminación de la retención en origen sobre la distribución de beneficios a los accionistas o partícipes no residentes que practica el país donde se encuentra localizada la sociedad filial. La adopción de esta medida evita que se produzca el fenómeno de la doble imposición jurídica, dado que las rentas recibidas por la sociedad matriz o el establecimiento permanente serán gravadas solamente por el Estado miembro exportador de capital ${ }^{82}$. En íntima conexión con el precepto señalado, el artículo 7

\footnotetext{
${ }^{81}$ GARCÍA PRATS, F. A., «La delimitación objetiva de las rentas... cit., pp. 109 y siguientes».

${ }^{82}$ Piénsese en el ejemplo de una sociedad matriz M, residente en España, que participa al $20 \%$ una sociedad filial F, residente en Alemania. Sin la aplicación de la
} 
de la Directiva 2011/96/UE dispone que la expresión "retención en origen" no comprenderá el pago anticipado o previo (descuento previo) del impuesto de sociedades al Estado miembro en el que la sociedad filial esté situada, respecto de la distribución de beneficios realizada a la sociedad matriz. El significado del artículo 7 de la Directiva 2011/96/UE reitera y complementa el mandato establecido en el artículo 5 de dicho texto normativo, aunque expresado de manera defectuosa. La retención en origen no afecta solamente al impuesto sobre sociedades sino también cualquier tasa, derecho o exacción que comprenda una retención en origen sobre los beneficios distribuidos por las sociedades filiales y sus matrices, con independencia de la calificación que le atribuya el Derecho nacional ${ }^{83}$. Como afirma Ruiz ${ }^{84}$, "no depende cómo se denomine en la normativa tributaria nacional o de qué régimen forme parte, sino únicamente de sus efectos".

En línea con los ejemplos anteriormente expuestos, debe aclararse que el método previsto por la Directiva 2011/96/UE para evitar que se produzca el fenómeno de la doble imposición jurídica es el de la exención íntegra en la fuente mediante la eliminación de la retención en origen ${ }^{85}$.

Directiva 2011/96/UE, los beneficios distribuidos por la sociedad filial $\mathrm{F}$ a la sociedad matriz $\mathrm{M}$ son gravadas mediante una retención en el país donde se ha generado dicha renta, es decir, en Alemania, en virtud de la aplicación del punto de conexión real que legitima a aquella jurisdicción a someter a exacción las rentas generadas en su territorio. Posteriormente, el Estado miembro de residencia de la sociedad matriz M someterá a imposición nuevamente esos beneficios mediante la obligación personal de dicha entidad de contribuir al erario público por sus rentas mundiales. Con lo cual, el solapamiento de los criterios de conexión personales y territoriales sobre el mismo contribuyente, la misma manifestación de riqueza, por dos soberanías fiscales distintas en el mismo periodo de tiempo daría lugar al fenómeno de la doble imposición internacional. Sin embargo, la aplicación del artículo 5 de la Directiva 2011/96/UE evita que se produzca el supuesto anterior en tanto en cuanto Alemania no podrá aplicar la retención en origen que se devengaría en su jurisdicción por la percepción de los beneficios distribuidos a la sociedad matriz M no residente en aquel país. Por su parte, el Estado miembro donde se encuentra domiciliada la sociedad matriz M será la única jurisdicción fiscal que podrá someter a exacción esas rentas por aplicación del principio personal que, en ese caso, será la condición de residente fiscal de la entidad M referida evitándose el fenómeno de la doble imposición jurídica.

${ }^{83}$ Sentencia del Tribunal de Justicia de las Comunidades Europeas, asunto Fazenda Pública y Epson Europe Bv, ERC 2000, párrafo 13; asunto Océ van der Grinten NV \& Commissioners of Inland Revenue C-58/01, de fecha 25 de septiembre de 2003, apartados 46 y 47; Athinaïki Zythopoiïa, apartados 26 y 27.

${ }^{84}$ RUIZ HIDALGO, C., Tributación ... cit., pp. 76 y siguientes.

${ }^{85}$ Cuestión distinta es que los beneficios que la sociedad matriz $\mathrm{M}$ recibe de la sociedad filial F sean gravados en el país de residencia de la primera donde correlativamente se aplique, en su caso, el método de la imputación para evitar que se produzca el fenómeno de la doble imposición internacional económica o colectiva. O, por el contrario, si el Estado miembro donde radica la sociedad matriz $\mathrm{M}$ optara por exonerar la percepción de sus beneficios por parte de aquélla, igualmente no se produciría ninguno de los dos fenómenos de doble imposición internacional. 
Centrándonos en el espectro de la doble imposición jurídica, desde el punto de vista de la equidad internacional, puede entenderse beneficioso la aplicación del método de la exención íntegra para evitar el fenómeno de la doble imposición internacional jurídica en tanto en cuanto existiría un reparto de las bases imponibles para las jurisdicciones fiscales afectadas. Por un lado, el país de origen recaudará mediante el impuesto sobre sociedades los beneficios obtenidos por la entidad filial, renunciando a la aplicación de la retención en origen a los accionistas o partícipes no residentes. Por otro, el país de residencia de la sociedad matriz podrá gravar esos beneficios, sin perjuicio de las medidas que debiera adoptar (mediante el método de exención o imputación) para evitar la correlativa y disociable doble imposición internacional económica. A su vez, la eliminación de la retención en origen que consigue evitar que se produzca la doble imposición jurídica favorece la neutralidad fiscal en la exportación de capitales en tanto en cuanto el país de la fuente renuncia a tributación sobre la repatriación de beneficios a los no residentes siendo el país de residencia de la sociedad matriz beneficiaria el que podrá gravar dichos beneficios, sin que se sometan a exacción manifestaciones de riqueza ficticias o pudieran generarse supuestos exacciones confiscatorias.

La eliminación de la retención en la fuente constituye un avance muy importante para evitar el fenómeno de la doble imposición internacional jurídica en el ámbito del mercado interior europeo que no ha resultado tan sencillo en el marco de los convenios de doble imposición de la OCDE. La aplicación del método de la exención íntegra en la fuente respecto de la distribución de beneficios societarios transnacionales implica el acotamiento y eliminación de los supuestos de doble imposición internacional en el mercado interior europeo dentro del ámbito de aplicación de la presente Directiva 2011/96/UE, quedando pues excluidos de aplicación aquellos casos no comprendidos en los ámbitos objetivo y subjetivo ni que cumplan los requisitos materiales exigidos por la norma comunitaria. La medida contenida en el artículo 5 de la Directiva 2011/96/UE cumple con el objetivo de dicha norma de eliminar la retención en la fuente $y$, al mismo tiempo, la doble imposición internacional jurídica sobre la distribución de beneficios dentro de los grupos de sociedades comunitarios. En gran medida cumple igualmente con los fundamentos establecidos en dicha norma evitando restricciones a la libertad de circulación y favoreciendo la neutralidad fiscal.

Por otra parte, el artículo 6 de la Directiva 2011/96/UE dispone que el Estado miembro de la sociedad matriz no podrá percibir ninguna retención en origen sobre los beneficios que aquella sociedad reciba de su filial. La aplicación de una retención en origen en el sentido de este precepto se presenta como un supuesto poco común. No obstante, la norma establece una medida 
nítida de protección para evitar prácticas abusivas y fórmulas rocambolescas por parte de los Estados miembros para intentar compensar de manera directa o indirecta la pérdida recaudatoria con la aplicación de las medidas contenidas en la norma comunitaria que, además, se traduciría en un quebrantamiento de los objetivos esenciales y fundamentos de la Directiva 2011/96/UE. En estos términos, puede afirmarse que la medida contenida en el artículo 6 de la norma es un contrapeso de la establecida en el artículo 5 en tanto en cuanto la eliminación de la retención en origen establecida en este último precepto carecería de eficacia, si el Estado miembro de la sociedad matriz estableciera una retención por los beneficios recibidos por aquella de la entidad filial radicada en otro Estado miembro de la Unión Europea, al tener que soportar un pago a cuenta en el impuesto sobre sociedades junto a los correspondientes costes burocráticos.

Finalmente, el artículo 7.2 de la Directiva 2011/96/UE establece que dicha norma no afectará a la aplicación de las disposiciones nacionales o, en su caso, a las establecidas en los convenios para evitar la doble imposición económica de dividendos, en particular, a aquellos preceptos referidos al pago de créditos fiscales a los beneficiarios de dividendos que resultaran más beneficiosos para el contribuyente, respecto de lo previsto en la propia Directiva 2011/96/UE. Desde el prisma garantista del contribuyente, el significado de dicho precepto debe tener un alcance restringido a aquellos supuestos en lo que de nítidamente le resulte más favorable en tanto en cuanto "los derechos que se derivan para los operadores económicos del artículo 5, apartado 1, de la misma son incondicionales y un Estado miembro no puede hacer depender su respeto de un convenio celebrado con otro Estado miembro (véase, en este sentido, la sentencia de 28 de enero de 1986, Comisión/ Francia, 270/83, Rec. p. 273, apartado 26) ${ }^{, 86}$. Este mandato legal subyace del principio de primacía del Derecho comunitario sobre las normas nacionales y los convenios de doble imposición suscrito por los países comunitarios, así como la obligatoriedad de que los convenios internacionales concertados por los socios comunitarios deban adecuarse a lo previsto en el Tratado de Funcionamiento de la Unión Europea (ex. artículo 351 del Tratado de Funcionamiento de la Unión Europea).

En conclusión, como ya se ha manifestado en páginas anteriores, la Directiva 2011/96/UE constituye avance importante en la lucha contra la

\footnotetext{
${ }^{86}$ Sentencia del Tribunal de Justicia de las Comunidades Europeas, asunto C-294/99, Athinaiki Zythopoiia A.E., de fecha 4 de octubre de 2001. En las conclusiones del Abogado General Sr. Siegbert Alber presentadas, en fecha 10 de mayo de 2001, se argumentaba que "las normas que sólo formen parte de la compensación de intereses entre los Estados contratantes respecto a la asignación de los ingresos tributarios correspondientes, pero que no eviten directamente la doble imposición, no formarán parte del ámbito de aplicación del artículo 7, apartado 2, de la Directiva”.
} 
doble imposición internacional en el mercado interior europeo, amén de la cuestiones problemáticas de aplicación de la norma comunitaria que se han expuesto a lo largo del presente estudio.

\section{DIRECTIVA 2011/96/UE VS MODELO DE CONVENIO DE LA OCDE: AVANCES DE LA NORMATIVA FISCAL COMUNITARIA, RESPECTO AL MODELO DE CONVENIO DE LA OCDE EN LOS SUPUESTOS DE DOBLE IMPOSICIÓN SOBRE LA DISTRIBUCIÓN DE BENEFICIOS}

En el presente apartado, toca el turno a realizar un estudio comparativo de las disposiciones contenidas en el Modelo de Convenio de la OCDE con los preceptos estudiados en la Directiva 2011/96/UE que nos arroje algo de luz acerca de los avances logrados en dicha norma fiscal comunitaria. Con carácter previo a dicho examen, debe subrayarse que serán objeto de examen aquellas cuestiones relacionadas en ambas normativas referidas exclusivamente al fenómeno de la doble imposición haciendo abstracción de otra serie de aspectos, tales como el principio de no discriminación previsto en el artículo 24 del Modelo de Convenio de la OCDE frente a una acepción más amplia del principio de no discriminación recogido en el artículo 18 del Tratado de Funcionamiento de la Unión Europea ${ }^{87}$; o la naturaleza jurídico-institucional de las normas comunitarias que emanan de instituciones compuestas por todos los Estados miembros que, actualmente, asciende a 27 países frente a la voluntad contractual generalmente bilateral que se presenta en la constatación de los convenios suscritos entre los Estados para evitar la doble imposición internacional.

Centrándonos ahora en el estudio en los progresos alcanzados por la Directiva 2011/96/UE, respecto del Modelo de Convenio de la OCDE que los Estados miembros toman como base para la negociación y firma de los convenios de doble imposición en el mercado interior europeo, cabría citar, con carácter preliminar, el ámbito subjetivo de aplicación de la Directiva 2011/96/UE que sólo comprende el impuesto sobre sociedades e impuesto sobre la renta de no residentes (para los establecimientos permanentes y accionistas y partícipes no residentes), y dentro del mismo, sólo determinados contribuyentes. Por el contrario, el Modelo de Convenio de la OCDE comprende el impuesto sobre la renta de las personas físicas, el impuesto sobre sociedades y el impuesto sobre la renta de no residentes.

${ }^{87}$ Vid. SANTA-BÁRBARA RUPÉREZ, J., La no discriminación fiscal, Madrid 2001. SOUSA SANTOS AGUIAR, N. T., «La fiscalidad de los beneficios... cit., pp. 3-72». MARÍN BENÍTEZ, G., «Fiscalidad de los dividendos transfronterizos... cit., pp. 3-44». 
Respecto a los sujetos pasivos, los impuestos comprendidos en el Modelo de Convenio de la OCDE albergan a todos los residentes fiscales sujetos a aquellos, a diferencia de la Directiva 2011/96/UE que incardina determinadas sociedades mercantiles (excluyendo al resto de sujetos pasivos) y a los establecimientos permanentes. Del mismo modo, cabe hacer una matización en el sentido de que el Modelo de Convenio de la OCDE proyecta su aplicación a los residentes fiscales sujetos a aquellos impuestos, pero, a su vez, también se aplica a los nacionales de los países signatarios, en lo referido a la aplicación del principio de no discriminación previsto en el artículo 24 de dicho modelo de convenio. Por su parte, la Directiva 2011/96/UE se limita a hacer referencia a unos sujetos pasivos concretos que cumplan determinados requisitos, a saber, algunas formas societarias previstas en el anexo, que estén sujetas y no exentas y, en lo que interesa a la presente cuestión, que tengan su domicilio fiscal en cualquier Estado miembro de la Unión Europea. Por añadidura, la Directiva 2011/96/UE solamente se aplica a determinadas sociedades y establecimientos permanentes pertenecientes a un grupo societario con una participación mínima del 10\%. Por el contrario, el Modelo de Convenio de la OCDE se aplica también a las personas físicas, residentes y no residentes, así como a todos los sujetos pasivos del impuesto sobre sociedades, lo cual denota una aplicación amplia de su ámbito en la lucha contra el fenómeno de la doble imposición internacional.

Por otra parte, la eliminación de la retención en origen se presenta como uno de los principales avances alcanzados por la Directiva 2011/96/UE. El artículo 10 del Modelo de Convenio de la OCDE contempla la retención en el país fuente donde se ha generado la renta distribuida a la otra jurisdicción comunitaria con una limitación en los tipos de gravamen que oscilan entre el $5 \%$ y el $15 \%$, con carácter general. Cuando se produce la retención en la fuente, la doble imposición internacional sólo podría eliminarse, si el tipo de gravamen del país de residencia de la sociedad matriz receptora de los dividendos es igual o inferior que el tipo impositivo nominal del Estado de la fuente. Pero, si el tipo de gravamen es superior, se producirá la doble imposición jurídica, y si el método para evitar la doble imposición prevista en el convenio es el de la imputación ordinaria, no podrían soslayarse las consecuencias nocivas de dicho fenómeno sino paliarse. Por ello, es notorio el progreso alcanzado por la Directiva 2011/96/UE al contemplar en el artículo 5 la eliminación de la retención en origen evitando el fenómeno de la doble imposición jurídica ${ }^{88}$;

88 SÁNCHEZ JIMÉNEZ, Ma . A., La doble imposición... cit., pp. 206-207. La autora postula que esta solución es más positiva que las establecidas en las medidas unilaterales y convencionales por dos razones esenciales. La primera, desde el punto de vista formal, por resultar más ventajosa la vía de una Directiva aplicable de manera uniforme a todos los Estados miembros, respecto de los convenios de doble imposición bilateral. Y la segunda, por 
aunque, desde un principio, habría sido deseable extender la eliminación de la retención en la fuente a todas las empresas sujetas al impuesto sobre sociedades y al impuesto sobre la renta ${ }^{89}$.

Los métodos previstos en el artículo 4 de la Directiva 2011/96/UE para evitar o, en su caso, eliminar el fenómeno de la doble imposición internacional económica erigen otro de los progresos alcanzados por la norma comunitaria, respecto al Modelo de Convenio de la OCDE. La Directiva 2011/96/UE faculta a los Estados miembros a aplicar el método de la exención íntegra a las rentas derivadas de beneficios distribuidos de otra entidad filial domiciliada en algunos de los países miembros de la Unión Europea. De este modo, se evitaría el fenómeno de la doble imposición internacional económica. $\mathrm{O}$, en su defecto, el método de la imputación ordinaria que presenta las limitaciones e inconvenientes ya expuestos.

Otro de los aspectos significativos donde la Directiva 2011/96/UE evidencia un importante avance en la lucha contra la doble imposición sobre los beneficios distribuidos en el ámbito comunitario estriba en la reducción del porcentaje mínimo de participación de la sociedad matriz en la entidad filial domiciliada en otro Estado miembro, a diferencia de lo previsto en el Modelo de Convenio de la OCDE $^{90}$. La Directiva 2011/96/UE consigue normalizar esta situación. No obstante, reiteramos la importancia de flexibilizar la exigencia del porcentaje mínimo de participación de las sociedades matrices en las entidades filiales para poder aplicarse las medidas previstas para evitar el fenómeno de la doble imposición en sus dos modalidades.

Por otro lado, revisten especial importancia los mecanismos de resolución de conflictos jurídicos-tributarios que presenta la Directiva 2011/96/UE frente al de los convenios de doble imposición internacional. Así, cualquier discrepancia en la aplicación o interpretación de la Directiva 2011/96/UE permite al contribuyente acudir a las instancias judiciales nacionales y, posteriormente, a las instancias judiciales europeas, es decir al Tribunal de Justicia de la Unión Europea (ex. artículos 256 y siguientes del Tratado de Funcionamiento de la

razones de practicidad, en tanto en cuanto evitan que se produzca el fenómeno de la doble imposición, y en consecuencia, no resultando preceptiva la aplicación de medidas correctoras.

${ }^{89}$ DE LA MAZA GARCÍA, J., «Orientaciones de la Comisión... cit., p. 4».

${ }^{90}$ Un ejemplo empírico podemos encontrarlo en los convenios de doble imposición firmados por España donde se observa la fijación de distintos porcentajes en función del convenio suscrito suele ser, con carácter general, entre el 5\% y el 15\%. Esta dispersión podría generar distorsiones en la localización de capitales en el mercado interior europeo fomentando la constitución de empresas no allí donde lo soliciten las necesidades del mercado sino donde se cumplan las condiciones de optimización fiscal, conforme a la red de convenios de doble imposición vigentes en el marco jurídico comunitario. 
Unión Europea). El contribuyente también podrá solicitar que la jurisdicción nacional eleve una cuestión prejudicial al Tribunal de Justicia de la Unión Europea para que se pronuncie sobre algún precepto o cuestión relacionada con la Directiva 2011/96/UE, a los efectos de poder aplicarse íntegramente las medidas previstas en la misma para evitar la doble imposición. O, incluso, como se aludiera en páginas anteriores, el contribuyente tendrá posibilidad de solicitar la tutela cautelar en aplicación de la norma que contraríe el Derecho jurídico-tributario europeo. Por el contrario, el Modelo de Convenio de la OCDE prevé el mecanismo del procedimiento amistoso que en esencia comprende un procedimiento de naturaleza diplomática en el que los Estados contratantes deben intentar alcanzar un acuerdo, pero sin que exista la obligación de conseguirlo. Esta limitación deja la responsabilidad de solventar las controversias derivadas de la aplicación e interpretación del convenio a las instancias judiciales nacionales de cada uno de los países signatarios con el consiguiente riesgo de que se produzcan resoluciones judiciales contradictorias sobre el significado, alcance, efectos, etc. de la misma cláusula convencional en función del país en el que se someta la cuestión a contienda judicial ${ }^{91}$.

Por otra parte, la aprobación y entrada en vigor de la Directiva 2011/96/UE emana de las exigencias jurídico-económicas enunciadas en los objetivos del Tratado de la Unión Europea, lo cual evidencia un dinamismo en la ampliación y mejora de la norma, como puede constatarse en que la misma erige una versión mejorada y ampliada de la Directiva 90/435/CE, la cual ha sido objeto de diferentes modificaciones con incidencia positiva para el contribuyente que opera en el mercado interior europeo, además de las aportaciones que siguen emanando de la jurisprudencia comunitaria. Este dinamismo se traduce en la aprobación y evolución de otras normas comunitarias tendentes a evitar el fenómeno de la doble imposición en sus dos modalidades sobre diferentes categorías de renta, como sucede, por ejemplo, con la Directiva 2003/49/CE del Consejo de 3 de junio, relativa a un régimen fiscal común aplicable a los pagos de intereses y cánones efectuados entre sociedades asociadas de diferentes Estados miembros, la Directiva 2009/133/CE del Consejo, de 19 de octubre de 2009, relativa al régimen fiscal común aplicable a las fusiones, escisiones, escisiones parciales, aportaciones de activos y canjes de acciones realizados entre sociedades de diferentes Estados miembros y al traslado del domicilio social de una SE o una SCE de un Estado miembro a otro o el Convenio de 23 de julio de 1990 relativo a la supresión de la doble imposición en caso de corrección de los beneficios de empresas asociadas. Por contra, la evolución, ampliación y mejora de las disposiciones previstas en los convenios para

\footnotetext{
${ }^{91}$ No obstante, cabe interpretar los preceptos del convenio de doble imposición en cuestión de manera sistemática, respecto a su incidencia en mayor o menor medida en el mercado interior europeo. Vid. CALDERÓN CARRERO, J. M., <<Algunas consideraciones en torno... cit.
} 
evitar la doble imposición no está supeditada más que a la voluntad contractual de tan sólo dos países que generalmente intervienen en la concertación de aquel, en consonancia con los intereses de ambas jurisdicciones y las exigencias económicas y de justicia tributaria existentes en sus respectivos sistemas fiscales.

Otro aspecto esencial íntimamente ligado a todas las cuestiones tratadas en este apartado es la homogeneidad en la aplicación de la Directiva 2011/96/UE frente a la heterogeneidad o bilateralidad que presentan los convenios de doble imposición. La Directiva 2011/96/UE será aplicable de manera uniforme a todos los grupos societarios comunitarios que operan en el mercado interior europeo, sin perjuicio de algunas particularidades que los Estados miembros hayan podido introducir al transponer dicha norma a su ordenamiento jurídico ${ }^{92}$. De este modo, la aplicación de la Directiva 2011/96/UE permite evitar que se produzcan los fenómenos de la doble imposición internacional jurídica y económica, con carácter general. Mientras que, en el marco de los convenios de doble imposición suscritos entre los socios comunitarios, con carácter general, se producirá la doble imposición al repartirse los Estados signatarios el poder tributario para someter a exacción las distintas fuentes de renta en la mayoría de los casos. Y aquella se eliminará solamente en supuestos específicos, conforme a lo estipulado en las cláusulas de los diferentes convenios y los tipos de gravamen previstos en sus respectivas legislaciones tributarias nacionales. Lo cual puede traducirse en una discriminación para el resto de contribuyentes que operan en idénticas condiciones en el mercado interior europeo.

Finalmente, un aspecto que, a nuestro modesto parecer, no refleja un avance de la Directiva 2011/96/UE frente a los convenios de doble imposición es el referido a las definiciones que no abundan en la norma comunitaria. Por el contrario, el Modelo del Convenio de la OCDE suelen tener definiciones más precisas $\mathrm{y}$, en cualquier caso, aquellas son integradas por los comentarios al Modelo de Convenio de la OCDE, a los cuales se les reconoce el valor jurídico como instrumento hermenéutico para la interpretación de los convenios de doble imposición. Por el contrario, aquellas nociones o aspectos no definidos en la Directiva 2011/96/UE parecen hacer remisión a los diferentes sistemas tributarios de cada uno de los países miembros y/o a la ardua tarea de acudir a los tribunales nacionales o al Tribunal de Justicia de la Unión Europea. Siendo pues recomendable que el Modelo de Convenio de la OCDE pudiera erigirse como un instrumento integrador de esta deficiencia interpretado dentro del contexto de fundamentos y objetivos de los Tratados de la Unión Europea.

${ }^{92}$ Además de las facultades concedidas por la norma comunitaria, por ejemplo, las medidas previstas en los artículos 1.2 o 7.2 . 


\section{REFERENCIAS BIBLIOGRÁFICAS}

- ARIAS ABELLÁN, M. D., «Impuesto sobre Sociedades; la deducción por doble imposición de dividendos e internacional en las entidades financieras», en Revista Española de Derecho Financiero (Madrid), 53 (1987) 31-38.

- CALDERÓN CARRERO, J. M., «Algunas consideraciones en torno a la interrelación entre los convenios de doble imposición y el Derecho comunitario europeo: ¿Hacia la "comunitarización de los CDIS"?», en Documentos (Madrid), 4/02 (2001) 1-63.

- CALDERÓN CARRERO, J. M., y MARTÍN JIMÉNEZ, A., «La Directiva relativa al sistema común de imposición aplicable en el caso de sociedades matrices y filiales de diferentes Estados miembros», en Convenios Fiscales Internacionales y Fiscalidad de la Unión Europea, Valencia 2010, pp. 1077-1121.

- COMISIÓN DE LAS COMUNIDADES EUROPEAS, «Communication de la Commission au Conseil et au Parlement Europeen consecutive aux conclusions du Comité de reflexión preside par O. Ruding et portant sur les orientations en matiere de fiscalité des entreprises daus le cadre de l'approfondissement du marché intérieur», en SEC (Bruselas), 92 (1992) 1118 final.

- COMISIÓN, «Hacia un mercado interior sin obstáculos fiscales. Una estrategia destinada a dotar a las empresas de una base imponible consolidada del impuesto sobre sociedades para sus actividades a escala comunitaria», en COM (Bruselas), (2001) 582 final.

- CORRIENTE CÓRDOBA, J. A., Valoración jurídica de los preámbulos de los tratados internacionales, Pamplona 1973.

- DE LA CUEVA GONZÁLEZ-COTERA, A., «La eliminación de la doble imposición económica de dividendos en la Unión Europea», en Revista de Contabilidad y Tributación (Madrid), 206/29 (2000) 49-94.

- DE LA MAZA GARCÍA, J., «Orientaciones de la Comisión sobre fiscalidad de las empresas en el ámbito del mercado interior», en Documentos (Madrid), (1992) 1-5.

- FABRA VALLS, M., «Contraste entre la Directiva sobre matrices y filiales y las medidas para evitar la doble imposición económica por dividendos en 
el Impuesto sobre Sociedades español», en Noticias de la Unión Europea (Valencia), 244 (2005) 71-90.

- GARCÍA CALVENTE, Y., «El régimen de información en la Propuesta de Directiva sobre imposición mínima de los intereses», en Impuestos (Madrid), 162 (2000) 694-703.

- GARCÍA PRATS, F. A., «La delimitación objetiva de las rentas afectadas por la Directiva 90/435/CEE: el concepto de beneficios distribuidos entre sociedades matrices y filiales», en Noticias de la Unión Europea (Valencia), 251 (2005) 91-121.

- GONZÁLEZ ORTIZ, D., «La Directiva 90/435/CEE desde la perspectiva de los principios constitucionales de justicia tributaria», en Noticias de la Unión Europea (Valencia), 244 (2005) 91-97.

- IZQUIERDO LLANES, G., El futuro de la tributación del capital en Europa, Madrid 1997.

- LETE ACHIRICA, C., «Régimen fiscal de las distribuciones de beneficios entre sociedades filiales y sociedades matrices», en Impuestos (Madrid), 2 (1996) 431-446.

- LÓPEZ ESPADAFOR, C. M., «Consideraciones sobre neutralidad fiscal en el ámbito empresarial», en Revista de Contabilidad y Tributación (Madrid), 262 (2005) 103-140.

- LÓPEZ RODRÍGUEZ, J., «El concepto de beneficiario efectivo en la Directiva europea de intereses y cánones», en Revista de Contabilidad y Tributación (Madrid), 358 (2013) 31-60.

- MANGAS MARTÍN, A., LIÑÁN NOGUERAS, D. J., Instituciones y derecho de la Unión europea, Madrid 2016.

- MARÍN BENÍTEZ, G., «Fiscalidad de los dividendos transfronterizos en la Unión Europea: sobre la adecuación de la normativa española al derecho comunitario», en Revista de Contabilidad y Tributación (Madrid), 271 (2005) $3-44$.

- OCDE, Model Tax Convention on Income and on Capital: Condensed Version 2017. París 2017. 
- PALACÍN SOTILLOS, R., «El procedimiento amistoso y el arbitraje como instrumento para evitar la doble imposición internacional», en Manual de Fiscalidad Internacional, Madrid 2004, pp. 1069-1110.

- PALAO TABOADA, C., «La aplicación de los convenios de doble imposición a las sociedades personalistas: el informe de la OCDE de 1999»), en Revista de Contabilidad y Tributación (Madrid), 209-210 / 49 (2000) 57-72.

- PRÓSPER ALMAGRO, A. B., «El nuevo escenario jurídico de la tributación de los dividendos entre España y los Estados Unidos de América», en Revista de Contabilidad y Tributación (Madrid), 374 / 34 (2014) 17-52.

- RODRÍGUEZ ONDARZA, J. A., «Fiscalidad de la inversión societaria: un estudio comparado para la Unión Europea», en Hacienda Pública Española (Madrid), 136 (1996) 109-143.

- RUBIO GUERRERO, J. J., «Los principios básicos de la fiscalidad internacional y la doble imposición internacional», en Manual de Fiscalidad Internacional, Madrid 2001, pp. 40-69.

- RUDING, «Informe del Comité Ruding: conclusiones y recomendaciones del Comité de Expertos Independientes sobre la imposición de sociedades», in Office for oficial Publications of the European Communities (Bruselas), (1992).

- RUIZ HIDALGO, C., Tributación de la empresa en la Unión Europea, Madrid-Barcelona 2002.

- SÁNCHEZ JIMÉNEZ, Ma . A., La doble imposición internacional en la Unión Europa. Especial consideración del Impuesto de Sociedades, Madrid 1995.

- SANTA-BÁRBARA RUPÉREZ, J., La no discriminación fiscal, Madrid 2001.

- SOUSA SANTOS AGUIAR, N. T., «La fiscalidad de los beneficios societarios y de los capitales en la Unión europea. Principios fundamentales», en Revista de Contabilidad y Tributación (Madrid), 262 (2005) 3-72.

- VARIOS, La armonización fiscal en la comunidad económica europea y el sistema tributario español: incidencia y convergencia, Madrid 1990.

- VOGEL, K., «Which method should the European Community adopt for the avoidance of double taxation?», in Bulletin-Tax Treatry Monitor (Ámsterdam), $56 / 1$ (2002) 4-10. 